\title{
Monumentos europeos para héroes centroamericanos: primeros años de los hermanos Durini en los mercados artísticos de El Salvador y Honduras $(1880-1883)^{*}$
}

\author{
Mauricio Oviedo Salazar ** \\ Leonardo Santamaría Montero****
}

Recibido el 27 de febrero de 2019; aceptado el 6 de mayo de 2019

\section{RESUMEN}

El objetivo de este artículo es estudiar los primeros movimientos comerciales de los hermanos suizo-italianos Lorenzo y Francisco Durini Vasalli, artistas y comerciantes de profesión, en el floreciente mercado artístico de la región centroamericana. El trabajo se delimita temporalmente desde 1880 hasta 1883, y espacialmente a El Salvador y Honduras. Su base fundamental son un gran número de fuentes primarias provenientes de El Salvador, Honduras y Costa Rica. Además, se propone que los monumentos contratados con los Durini en esos años contribuyeron a la imaginería oficialista de las repúblicas de El Salvador y Honduras.

* Este artículo se basa en parte de los resultados obtenidos en el proyecto de investigación "Los Durini: redes de mercado cultural en Centroamérica" (cod. B5216), realizado entre los años 2015 y 2016 en el Instituto de Investigaciones en Arte (IIArte) y financiado por la Vicerrectoría de Investigación de la Universidad de Costa Rica.

** Universidad de Groningen, Países Bajos. Correo electrónico: M.G.Oviedo.Salazar@rug.nl. ORCID: https://orcid.org/0000-0002-8590-8805.

*** Universidad de Costa Rica, Costa Rica. Correo electrónico: leonardo.santamaria@ucr.ac.cr. ORCID: https://orcid.org/0000-0002-4733-2147. 
Palabras clave: Hermanos Durini, monumentos, comercio artístico internacional, Centroamérica, Francisco Morazán, siglo XIX.

\title{
European monuments to Central American heroes: The first years of the Durini brothers within El Salvador and Honduras Artistic Market (1880-1883)
}

\begin{abstract}
The aim of this paper is to study the first commercial movements by the Swiss-Italian brothers Lorenzo and Francisco Durini Vasalli, artists and businessmen by profession, in the flourishing artistic market of the Central American region. The article is delimited temporarily from 1880 to 1883, and spatially to El Salvador and Honduras. Its fundamental baseline is a prominent variety of primary sources coming from El Salvador, Honduras and Costa Rica. In addition, it is proposed that the monuments commissioned to the Durini on those years contributed to the official imagery of El Salvador and Honduras republics.
\end{abstract}

Key words: Durini brothers, monuments, international artistic commerce, Central America, Francisco Morazán, $19^{\text {th }}$ Century.

\section{INTRODUCCIÓN}

T os siglos XVIII y XIX son de los períodos más relevantes para la historia $\amalg$ de América. Éstos son los siglos de las independencias y, por lo tanto, momento para la reformulación de relaciones comerciales entre el continente y las demás naciones del mundo. Además, son las centurias en las que se desarrollaron con fuerza gran variedad de corrientes intelectuales y culturales, movimientos filosóficos unidos a teorías sociales y económicas, donde los objetivos de orden y progreso se volvieron predominantes en muchos de los nacientes gobiernos americanos.

Dichos ideales tenían como modelo a seguir a una Europa representada principalmente por países como Francia e Inglaterra, sin embargo, en el ámbito de las artes visuales Italia seguía teniendo un papel esencial, como el guardián y heredero de los grandes maestros de la historia del arte occidental. ${ }^{1}$ Los ideales de belleza de la Antigüedad grecorromana, su percepción en

1 Gutiérrez, “Carrara nell’America Latina e creazione scultorea”, pp. 254-259; Gutiérrez, "Presencia de Italia en la pintura y la escultura de los países sudamericanos durante el siglo XIX”, pp. 35-46. 
el Renacimiento y la reformulación que tuvo en movimientos artísticos como el Neoclasicismo y el Romanticismo, ${ }^{2}$ son parte fundamental del imaginario que las naciones americanas buscaban para ilustrar sus territorios, en función de que a ojos del mundo los países se percibieran como progresistas y civilizados. ${ }^{3}$

Los anhelos de los gobernantes latinoamericanos eran conocidos por los comerciantes europeos, entre ellos artistas, quienes vieron en el Nuevo Mundo un suelo fértil para la producción artística y la expansión de sus negocios, además de la inserción de nuevas corrientes artísticas, como el Historicismo, el cual resultaba adecuado por su capacidad de adaptación estilística y estructural según las exigencias de los clientes y las funciones de cada inmueble. ${ }^{4}$ Por ello, los gobernantes centroamericanos importaron de Europa sus primeros monumentos a héroes nacionales. Éste es precisamente el caso de las obras contratadas con los hermanos suizo-italianos Lorenzo (1855-1905) y Francesco (Francisco) Durini Vasalli (1856-1920), cuyo caso corresponde al tema central del presente texto.

Artistas y comerciantes, los hermanos Durini ingresaron al mercado artístico de Latinoamérica en las últimas décadas del siglo XIX, con la producción de monumentos, edificios, mausoleos y una gran variedad de ornamentaciones, entre otros productos. Su huella es visible tanto en Suramérica como en Centroamérica y México. ${ }^{5}$ Su contribución a la creación de la imagen de las repúblicas liberales latinoamericanas es fundamental y, sin embargo, estudios enfocados directamente a sus métodos de trabajo y negocio en Centroamérica son escasos. Autores como Inés del Pino Martínez y Ernesto Capello le han dado un valor central a la obra de los Durini en el contexto suramericano, principalmente el ecuatoriano. ${ }^{6}$ Un repaso general de la obra de los hermanos fue elaborado por Pedro M. Durini, en donde los proyectos escultóricos y arquitectónicos en Centroamérica son incluidos. ${ }^{7}$ En cuanto a estudios enfocados a su impacto en la región centroamericana, los

2 Pavoni, Reviving the Renaissance: the use and abuse of the past in nineteenth-century Italian art and decoration; Toman, Neoclasicismo y romanticismo, pp.14-229.

3 Gutiérrez, Arquitectura y urbanismo en Iberoamérica, pp. 365-491; Santamaría, "Análisis de la conformación del diseño arquitectónico y ornamental del Teatro Nacional de Costa Rica”, pp. 211-214; Tavernor, Palladio and palladianism, pp. 181-209.

4 Pevsner, Historia de las tipologías arquitectónicas; Gutiérrez, Arquitectura y urbanismo en Iberoamérica, pp. 403-413; Santamaría, “Análisis de la conformación del diseño arquitectónico y ornamental del Teatro Nacional de Costa Rica”, pp. 169-183.

5 Durini, El Salvador Monumental y sus obras hermanas en América.

6 Capello, City at the Center of the World: Space, History, and Modernity in Quito; Pino, “Gestión y arte en el espacio público: la contribución de los "Durini” en América (18801930)".

7 Durini, El Salvador Monumental y sus obras hermanas en América. 
Durini son mencionados normalmente como parte de un proceso más grande vinculado a las artes visuales, la política o a las migraciones italianas a finales del siglo XIX. Esto es evidente en Luca Bochicchio, José Danilo Cifuentes, Juana Victoria González, Rodrigo Gutierrez Viñuales, José Vicente Torrejón, Rita Bariatti y Astrid Fischel. ${ }^{8}$ Hasta el momento no existe un estudio detallado sobre los diversos mecanismos de producción y contratación por parte de los Durini, menos aún en el ámbito centroamericano. La discusión se centra comúnmente en cómo su trabajo pertenece a una serie de discursos ideológicos y visuales del período, sin tomar en cuenta las diversas negociaciones y movimientos detrás de cada uno de los encargos. Es nuestro argumento que los Durini pueden ser utilizados como un estudio de caso y como un punto de partida. Al rastrear las redes de comercio artístico de sendos hermanos, podríamos dar inicio a una estructura más detallada de las relaciones entre las políticas migratorias, las artes visuales, los movimientos ideológicos, políticos y sociales, y el contexto económico en las últimas décadas del siglo XIX en Centroamérica. El elaborar un mapa de redes y relaciones más preciso es una base valiosa que contribuiría no sólo al fortalecimiento de la historiografía del arte centroamericano del siglo XIX, sino a la comprensión de una serie de transformaciones políticas y culturales que empiezan a acontecer a inicios del siglo siguiente.

Por este motivo, dedicamos este trabajo a determinar el inicio de la compleja red de comercio artístico creada por los hermanos Durini en la región centroamericana, focalizando nuestro estudio en lo que refiere a los monumentos contratados por los estados de El Salvador y Honduras en el período comprendido entre 1880 y 1883 . Durante estos tres años se formaron los primeros contactos de los suizo-italianos en la región. La inserción de los Durini en esta zona estuvo marcada por las necesidades artísticas existentes en los ámbitos político e intelectual, en donde se proponía generar imaginarios con los que el pueblo pudiese sentirse identificado, no sólo a lo interno de los estados nacionales, sino con el resto de Centroamérica, en consonancia con los contradictorios deseos salvadoreños y hondureños de formar nacionalismos particulares, y a la vez revivir la República Federal Centroa-

8 Bochicchio, "La contribución italiana a la imagen monumental —escultórica y arquitectónica - de la independencia en Honduras"; "Las esculturas de la Avenida Reforma como medio de identidad histórica guatemalteca"; González, "La impronta italiana en las esculturas del Cementerio General de Guatemala (1881-1920)”; Gutiérrez, “Carrara nell’America Latina e creazione scultorea"; Gutiérrez, "Presencia de Italia en la pintura y la escultura de los países sudamericanos durante el siglo XIX"; Torrejón, "Escultura monumental pública de Tegucigalpa”; Bariatti, Italianos en Costa Rica 1502-1952: de Cristóbal Colón a San Vito de Java; Fischel, El Teatro Nacional de Costa Rica: su historia. 
mericana, un ideal nutrido por las creencias del progresismo positivista latinoamericano. ${ }^{9}$

En tal contexto, los Durini confeccionaron monumentos escultóricos por encargo de los gobiernos de El Salvador y Honduras, quienes les solicitaron a los europeos obras conmemorativas a distintos héroes de la historia reciente de Centroamérica. Destaca el caso de los monumentos a Francisco Morazán, pues ambos fueron utilizados por los gobiernos salvadoreño y hondureño como un símbolo identitario oficialista, el cual pretendía exaltar el nacionalismo y a la vez el espíritu unionista centroamericano. En este artículo damos mayor énfasis a los monumentos a Morazán debido a que mediante éstos, Francisco Durini se movió del mercado salvadoreño al hondureño. Además, de acuerdo al análisis hecho de las respuestas y crónicas de la prensa en estos años, tales obras estatuarias fueron las que parecieron tener mayor impacto en el programa político de ambos países.

El Salvador y Honduras es el inicio de los Durini dentro del mercado artístico oficialista de la región. Dicho mercado estaba regido por una proliferación de concursos y contratos públicos generados por los estados centroamericanos, donde contratistas y artistas debían competir por obtener el trabajo. Muchas de estas contrataciones fueron ganadas por los Durini, no sólo en los años aquí estudiados, sino hacia finales del siglo XIX y principios del XX. La presencia constante de los hermanos en obras artísticas estatales permite especular que, empezando en El Salvador, los Durini desarrollaron, o se volvieron parte de una red social donde estaban involucradas tanto esferas políticas como intelectuales en Centroamérica.

Como la investigación está enfocada en el mercado artístico oficialista no hay mención en este artículo sobre los encargos privados y obras de tipo funerario (mausoleos y lápidas) vinculantes al negocio de los Durini en el período. Dicho trabajo se encuentra todavía pendiente. Tampoco nos referiremos a la obra arquitectónica de los Durini, pues hasta el momento la información sobre las construcciones de esos años ha sido tanto escasa como difusa.

En orden a elaborar una reconstrucción de la actividad artísticocomercial de los primeros años de los Durini en Centroamérica, hemos organizado el artículo en dos partes. Con el fin de contextualizar el arribo de los Durini a Centroamérica, primero nos dedicaremos brevemente a lo que conocemos de la vida de los hermanos previo a su llegada a la región. Seguidamente, nos concentraremos en lo que llegamos a descubrir sobre los

9 López, “Inventando tradiciones y héroes nacionales: El Salvador (1858-1930)”, pp. 5-9; Taracena, “Liberalismo y poder político en Centroamérica (1870-1929)”, pp. 190-193. 
diversos movimientos y encargos en los que los hermanos participaron entre 1880 y 1883, específicamente en las repúblicas de El Salvador y Honduras.

El artículo se basa en fuentes primarias resguardadas por el Archivo General de la Nación (El Salvador), el archivo digital del Diario Oficial de la República de El Salvador (http://www.diariooficial.gob.sv/), el Archivo Nacional de Honduras (Honduras), el Archivo Nacional de Costa Rica (Costa Rica) y la Biblioteca Nacional de Costa Rica (Costa Rica). Dichas fuentes corresponden a periódicos, actas y memorias gubernamentales. Además, visitamos San Salvador (El Salvador) y Tegucigalpa (Honduras) para estudiar y fotografiar los monumentos contratados con los Durini en el período comprendido entre 1880 y 1883.

El artículo no pretende analizar los monumentos desde el punto de vista estético, por lo que la mayor fuente de información no son las imágenes recabadas, sino lo que la prensa y los documentos estatales relatan sobre la actividad de los hermanos. En otras palabras, los análisis realizados se concentran en generar una coherencia narrativa en cuanto a los procesos de contratación y función de los encargos hechos a los Durini. En este sentido, el problema de investigación se abordó a partir del análisis y contrastación de fuentes primarias y secundarias, con la prioridad de encontrar similitudes narrativas entre las fuentes, y en el caso de encontrar diferencias, analizar qué tipo de problemas podrían generar éstas a la hora de configurar la red y los procesos de comercio artístico. Con la información recolectada creamos un estado de la cuestión que nos permitió elaborar una serie de hipótesis que proveyeron diversas líneas de investigación y un número de resultados posibles. Al corroborar las hipótesis con el material empírico recogido, se logró discernir cuáles vías podían ser seguidas y cuáles debían ser consideradas falseadas. Dicho procedimiento permitió determinar cuál hipótesis contaba con el mejor respaldo tanto empírico como lógico, y con el menor margen de conocimiento no corroborado.

\section{LOS DURINI Y CENTROAMÉRICA}

El contexto socioeconómico en la Europa del siglo XIX, especialmente en Italia, fue determinante en el curso de las rutas migratorias seguidas por la familia Durini Vasalli, por lo que nos referiremos sucintamente a dicho período. Seguidamente consagraremos un breve espacio a lo que sabemos de la Familia Durini y su vínculo a América, previo a las relaciones de los hermanos con El Salvador y Honduras. 


\section{BREVE CONTEXTO DE EUROPA Y LATINOAMÉRICA ENEL SIGLOXIX}

El comercio y la industria internacional se expandieron en Occidente a lo largo del siglo XIX gracias a las consecuencias de la revolución industrial, el final de las guerras napoleónicas (1815) y los procesos independistas de las colonias del imperio español (1810-1821). ${ }^{10}$ La creciente demanda europea de materias primas y alimentos requirió de más proveedores y un mercado internacional regido por el "libre comercio"; entonces, las naciones americanas perfilaron sus economías según un modelo focalizado en la exportación. ${ }^{11}$ De este modo, las economías europeas y latinoamericanas (incluyendo las centroamericanas) estrecharon sus vínculos comerciales. ${ }^{12}$

Además de atestiguar la formación de los estados nacionales y del mercado mundial, el siglo XIX también se caracterizó por el masivo éxodo de europeos dentro y fuera de Europa (especialmente hacia América), el cual fue motivado por la efervescencia política y las crisis económicas. ${ }^{13}$ Por ejemplo, se estima que en 1880 había entre 700000 y 800000 europeos en calidad de migrantes. ${ }^{14}$ ¿Por qué? En el caso de Italia, los novedosos sistemas industriales necesitaban de obreros especializados, lo cual relegó de la economía a cientos de personas y propició la emigración. ${ }^{15}$ De forma paralela, los nacientes estados decimonónicos necesitaban de mano de obra para una enorme variedad de proyectos, entre ellos la producción de obra pública (ferrocarriles, edificios, parques, monumentos, etcétera). Dichas condiciones estimularon la llegada de millares de europeos a América, pues, según las políticas predominantes en los gobiernos de la región, la inversión en inmigración extranjera era una prioridad. ${ }^{16}$

Con respecto a las políticas económicas latinoamericanas de nuestro período de estudio, debe señalarse que los estados jugaron un papel crucial en el devenir de las economías de las recién nacidas repúblicas liberales. Por un lado, los estados nacionales intervinieron y estimularon el comercio nacional; por el otro, los gobiernos dirigieron una numerosa cantidad de pro-

10 León, Evolución del comercio exterior y del transporte marítimo de Costa Rica: 1821-1900, p. 16.

11 Oviedo y Santamaría, "Mercato culturale: El nacimiento de la ornamentación de un Coliseo”, p. 34. Cf: León, Evolución del comercio exterior y del transporte marítimo de Costa Rica: $1821-1900$, pp. 16-17.

12 Lindo, “Economía y sociedad (1810-1870)”, pp. 186-190.

13 Oviedo y Santamaría, "Mercato culturale: El nacimiento de la ornamentación de un Coliseo", pp. 36-38.

14 Hobsbawn, La era del capital: 1848-1875, p. 203.

15 Oviedo y Santamaría, "Mercato culturale: El nacimiento de la ornamentación de un Coliseo", p. 38.

16 Ibíd., p. 37. 
yectos de infraestructura. ${ }^{17}$ Las obras de infraestructura contratadas por los estados latinoamericanos no se limitaron a estructuras concernientes a la producción agrícola y la exportación, pues las sociedades latinoamericanas también se preocuparon por el desarrollo arquitectónico y urbanístico de sus ciudades. En palabras de la historiadora costarricense Florencia Quesada Avendaño:

Las ciudades y especialmente las capitales latinoamericanas, estuvieron en el epicentro de las transformaciones y la modernización como representación de la nación y de ese ideal moderno de transformación. Entre más se asemejaran a las capitales europeas, casi como una fórmula mágica, sus elites pensaban que podían tener el pase seguro para engrosar las filas anheladas y dichosas del mundo civilizado. Las burguesías dominantes procuraron que la fisonomía edilicia creara el fiel reflejo de un país próspero y moderno, o mejor dicho la fachada de esa idea, que más bien fue focalizada y selectiva geográficamente. ${ }^{18}$

Tal proceso de modernización urbana se desarrolló en Latinoamérica con mayor potencia durante la segunda mitad del siglo XIX. En un contexto en el cual cientos de miles de europeos migraban hacia América en búsqueda de mejores condiciones de vida, a Latinoamérica llegaron numerosos escultores, pintores, canteros, arquitectos, ingenieros, operarios especializados y artesanos, quienes dinamizaron los mercados artísticos y constructivos del sub-continente. ${ }^{19}$ Los grandes clientes de dichos artistas, comerciantes y constructores fueron los gobiernos y las burguesías de cada país, pues las imágenes y los edificios les permitieron - tanto al Estado-nacional como a las élites económicas-construir las estructuras y los símbolos que les identificarían nacional e internacionalmente. ${ }^{20}$

Los Durini formaron parte de esta dinámica migratoria, trazando de esta manera lucrativas rutas comerciales entre América y Europa. Entre las décadas de 1850 y 1910, tres generaciones de los Durini participaron en los mercados artísticos de Suiza, Italia, Perú, México, Ecuador y las cinco repúblicas centroamericanas (Guatemala, Honduras, El Salvador, Nicaragua de Java, p. 20.

18 Quesada, “La modernización entre cafetales. San José, Costa Rica, 1880-1930”, p. 76.

19 Gutiérrez, “Carrara nell’ America Latina e creazione scultorea”.

20 Ibíd., Gutiérrez, "Presencia de Italia en la pintura y la escultura de los países sudamericanos durante el siglo XIX”. 
y Costa Rica). Dichas generaciones se configuraron estableciendo lazos familiares-comerciales en Perú, Guatemala, Costa Rica y Ecuador.

\section{LA FAMILIA DURINIVASALLI}

Para estudiar la historia de los Durini resulta fundamental consultar el libro del investigador ecuatoriano Ernesto Capello, titulado City at the Center of the World: Space, History, and Modernity in Quito (2011), específicamente el capítulo "The Durini Cosmopolis: Crafting a Hyphenated Vernacular Architecture". Asimismo, son de gran importancia los datos biográficos publicados por Pedro M. Durini, nieto de Lorenzo Durini Vasalli, en el libro El Salvador Monumental y sus obras hermanas en América (1996). ${ }^{21}$ También es muy valiosa la información contenida en dos textos sobre la vida y obra de los Durini, escritos por la arquitecta e investigadora ecuatoriana Inés del Pino Martínez. ${ }^{22}$ A continuación se presenta lo que sabemos sobre los Durini Vasalli y su llegada a Centroamérica.

Lorenzo y Francisco Durini Vasalli son hijos del escultor lombardo Giovanni (Juan) Durini (1826-1907) y de la suiza Elizabetta Vasalli (originaria de Tremona). ${ }^{23}$ Hacia inicios de la década de 1860, los Durini Vasalli se trasladaron a Lima, Perú, como parte de las migraciones europeas comentadas en la sección anterior. ${ }^{24}$ Ya establecidos en Perú, Giovanni Durini se

Durini, El Salvador Monumental y sus obras hermanas en América.

Pino, “Gestión y arte en el espacio público: la contribución de los "Durini” en América (1880-1930)”; Pino, Los Durini: Artífices del rostro moderno de Quito. Análisis de la arquitectura en un marco socio-histórico.

23 Santamaría y Oviedo, “Los hermanos Durini y las Casas de Corrección en Costa Rica”, p. 23. Se cree que la decisión de migrar está vinculada a la participación de Giovanni en las revueltas sucedidas en Italia, hoy conocidas bajo el nombre de il Risorgimento. Cf. Capello, City at the Center of the World: Space, History, and Modernity in Quito, p. 122; Hughes, Ticino. A History of the Cantons. Unfinished and Unpublished”.

24 Gracias a Gabriella Chiaramonte sabemos que ya para 1858 habían 3469 italianos residentes en el Perú, y para 1871, de los 5000 italianos ya establecidos en el país, habían al menos 3500 ubicados en Lima. Chiaramonte, “La migración italiana en América Latina. El caso peruano”, pp. 16-17.

La inmigración se da en parte gracias al auge económico que se da en el país suramericano a partir de la explotación del guano, el cual provocó el nacimiento de la oligarquía peruana. A dichos evento se añade que: "En la etapa republicana, la inmigración de [italianos] [...] se debe en gran medida a factores políticos, a raíz de Il Risorgimento [...] De esta manera muchos de ellos arriban a América Latina, en especial al Perú [...]”. Leonardini, Presencia e imagen femenina en la escultura italiana en el Perú del siglo XIX”, pp. 115-116.

Pero esto no es todo. Debemos recordar que Giovanni migró a Lima desde Tesino, y a pesar de ser lombardo, pareciera que su perfil en la región suramericana era ticinense. El guano y el salitre, más la construcción de infraestructura, como ferrocarriles, atraía a los suizos, especialmente a los de Tesino. Sabemos que Giovanni Durini perteneció a la comunidad suiza 
incorporó al mercado limeño de la marmolería y probablemente asumió a sus hijos como sus discípulos en su taller de escultura. ${ }^{25}$ Francisco y Lorenzo Durini fueron enviados por su padre a Génova para recibir formación artística y arquitectónica académica, esto con el objetivo de fortalecer y expandir el negocio familiar. ${ }^{26}$ Probablemente los hermanos Durini regresaron a Lima a mediados de la década de 1870 , pero no se tiene certeza de las fechas o los años de conclusión de sus estudios y de su regreso a América. En abril de 1879 Lorenzo Durini contrajo matrimonio con la peruana Juana Cáceres Luque, ${ }^{27}$ posteriormente los Durini Cáceres migraron a Tremona, donde nacieron los futuros herederos de la empresa familiar: Francisco Manuel y Pedro Durini Cáceres. ${ }^{28}$

Lorenzo y Francisco Durini Vasalli recibieron formación profesional en escultura y arquitectura, pero, ante todo, eran comerciantes. Debido al alto volumen de trabajo de los Durini, los hermanos manejaban sus negocios mediante sub-contrataciones en Europa y América. Para construir su red internacional de comercio artístico, a lo largo de la década de 1880 los Durini viajaron constantemente entre Europa y Centroamérica, lo cual les permitía negociar directamente en América, además de contratar y supervisar la ejecución de las obras y sus envíos en Europa. Durante su primera década en el mercado artístico centroamericano, los Durini colocaron importantes monumentos y numerosos mausoleos en los cinco países, la mayoría de piezas importadas de Carrara. ${ }^{29}$

\section{LOS DURINI EN CENTROAMÉRICA ENTRE 1880-1883: EL SALVADOR Y HONDURAS}

En esta segunda parte intentaremos mantener un orden cronológico con la mayor claridad posible, en función de que se visualicen cada uno de los movimientos realizados por los hermanos. Iniciamos con los proyectos de

en el Perú gracias a que su nombre aparece en el primer documento que conocemos hasta el momento de la Sociedad Suiza de Beneficencia Helvetia, fechado el 18 de mayo de 1882: Cámara de Comercio Suiza en el Perú, Presencia Suiza en el Perú, pp. 27, 148.

25 Gutiérrez, "Carrara nell'America Latina e creazione scultorea”.

26 Santamaría y Oviedo, "Los hermanos Durini y las Casas de Corrección en Costa Rica", p. 23. Cf. Capello, City at the Center of the World: Space, History, and Modernity in Quito, p. 122.

27 Zanutelli, La huella de Italia en el Perú, p. 216.

28 Tuvieron dos hijos y una hija: Francisco Manuel (1880-1970), Pedro (1882-1970) y Gemma Durini Cáceres (1889-这).

29 Gutiérrez, "Carrara nell’America Latina e creazione scultorea”. 
los Durini en El Salvador en los años establecidos, ${ }^{30}$ en donde se destaca la creación del monumento a Francisco Morazán (1880-1882) y los procesos sociopolíticos detrás de esa obra. A partir de la contratación de ese monumento, llegamos a tener mayor conocimiento sobre la participación de Lorenzo Durini en los negocios de su hermano en la república salvadoreña.

Seguidamente, pasaremos a Honduras, en donde los Durini erigieron una serie de monumentos a héroes nacionales hondureños (incluido Morazán), además de un monumento al general nicaragüense Máximo Jerez (18181881), encargado por parte del Gobierno de Honduras como un obsequio al Club Liberal de León, en Nicaragua. También en el caso de Honduras, mostraremos cuál pudo haber sido el papel de Lorenzo Durini en los contratos que tenía su hermano y cuál era el trasfondo político de las obras encargadas por los hondureños a Francisco Durini. Con los trabajos elaborados de 1880 a 1882, la fama de Francisco Durini llegó a difundirse fuera del continente americano, como lo demuestra la prensa italiana de 1882, de la que haremos un breve comentario.

\section{EL SALVADOR. FRANCISCO DURINI Y LORENZO DURINI (1880-1883): MONUMENTO A FRANCISCO MORAZÁN Y OTROS ENCARGOS}

A partir de la evidencia con la que contamos hasta el momento, consideramos que Francisco Durini fue quien logró establecer los primeros vínculos comerciales en Centroamérica; se dedicó al comercio e importación de esculturas manufacturadas en Europa, y a través de ello se abrió camino en el mercado artístico de la región centroamericana. ${ }^{31}$

Según Kharen Matute y Luca Bocchiccio, Francisco Durini emigró a Tegucigalpa (República de Honduras) en 1879, sin embargo, ambos autores

30

$$
\begin{aligned}
& \text { Salvador en años posteriores. Dichas obras serán objeto de estudio en futuras publicaciones. } \\
& \text { Santamaría y Oviedo, “Los hermanos Durini y las Casas de Corrección en Costa Rica”, p. } \\
& \text { 34. Cf. Cifuentes, "Las esculturas de la Avenida Reforma como medio de identidad histórica } \\
& \text { guatemalteca”; Pino, Los Durini: Artífices del rostro moderno de Quito. Análisis de la ar- } \\
& \text { quitectura en un marco socio-histórico; Fishel, El Teatro Nacional de Costa Rica: su histo- } \\
& \text { ria; González, "La impronta italiana en las esculturas del Cementerio General de Guatemala } \\
& \text { (1881-1920)”; Gutiérrez, “Carrara nell’America Latina e creazione scultorea”; Gutiérrez, } \\
& \text { "Presencia de Italia en la pintura y la escultura de los países sudamericanos durante el siglo } \\
& \text { XIX”; Torrejón, "Escultura monumental pública de Tegucigalpa”, Valdés, "Masones, libera- } \\
& \text { les y ultramontanos salvadoreños: debate político y constitucional en algunas publicaciones } \\
& \text { impresas, durante la etapa final del proceso de secularización del Estado salvadoreño (1885- } \\
& \text { 1886)”. }
\end{aligned}
$$

mos tener claro que los Durini volvieron a trabajar tanto en Honduras como en E 
no refieren a fuentes primarias, lo cual impide corroborar tal afirmación. ${ }^{32} \mathrm{El}$ registro más antiguo de la presencia de Durini en Centroamérica lo ubica primero en El Salvador. En el número correspondiente al 19 de septiembre de 1880 del Diario Oficial de aquella república, en la sección de "Telegramas", se indica que "Francisco A. Durini” arribó al puerto de La Libertad a bordo del vapor Coima, el cual provenía de "San Francisco California é [sic] intermedios". ${ }^{33} 1880$ parece ser el año oficial de llegada de Durini a la región, pues en un sello de la firma Durini Hermanos (Figura 1), utilizado en Costa Rica entre 1895 y 1897, se indica: "Establecidos en Centro-America [sic] el [sic] 1880". ${ }^{34}$

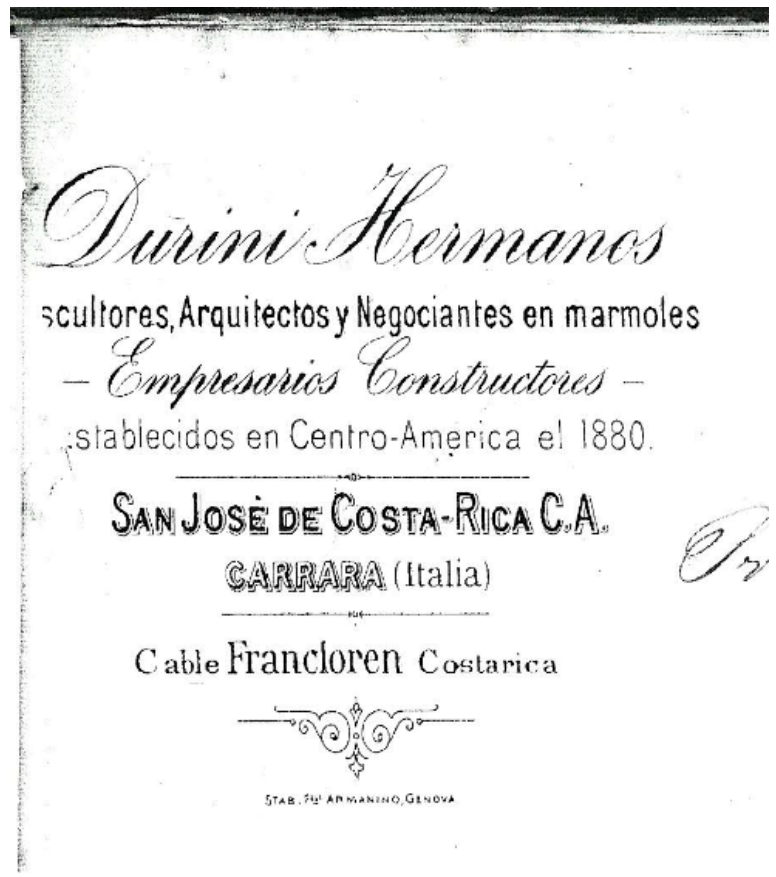

Figura 1. Sello de Durini Hermanos. 1895-1897.

Fuente: Archivo Nacional de Costa Rica.

Bochicchio, "La contribución italiana a la imagen monumental — escultórica y arquitectónica- de la independencia en Honduras”, p. 18; Durini, El Salvador Monumental y sus obras hermanas en América.

33 “Telegramas”, Diario Oficial, San Salvador, 19 de septiembre de 1880, p. 790.

34 “Carta de Durini Hermanos a Ángel Miguel Velázquez”, Costa Rica, 3 de junio de 1895, Archivo Nacional de Costa Rica, Fomento, signatura 1370, f. 13. 
El momento de la llegada de Durini a Centroamérica resultó propicio para el éxito de sus ulteriores negocios. Entonces el doctor Rafael Zaldívar (1834-1903) era el presidente de la República de El Salvador. Su gobierno gestó una serie de reformas liberales, las cuales pretendían enrumbar al Estado salvadoreño por la senda del progreso, la civilización y la modernización. ${ }^{35}$ Con estos ideales en mente, muchos de los programas intelectuales de la época estaban concentrados en "[...] forjar una identidad que cohesionara a los salvadoreños en un sentimiento compartido y, de ser posible, crear los héroes que sirvieran de modelo a las nuevas generaciones". ${ }^{36} \mathrm{El}$ arte fue fundamental para el desarrollo de tal proyecto nacionalista; esto se materializó con la erección de monumentos a héroes nacionales o centroamericanos, y con la creación de plazas dispuestas para la adoración pública de aquéllos. ${ }^{37}$ Por ello, desde 1875 en la prensa salvadoreña se hablaba de la importancia de honrar la memoria de los padres de la patria. Por ejemplo, en la edición del 14 de septiembre de 1875 del Diario Oficial, bajo el título "Entusiasmo Patriótico", leemos: "Cuando los pueblos no saben honrar la memoria de sus próceres; cuando no se rinde culto á la sublime religión del patriotismo; cuando va debilitándose el entusiasmo que produce el recuerdo de los grandes hechos [...] esos pueblos están cerca de su decadencia”. ${ }^{38}$

Sin embargo, en 1875 el culto a los héroes de El Salvador seguía siendo estrictamente ceremonial y discursivo, esto a falta de monumentos conmemorativos dispuestos en la capital de la república, ${ }^{39}$ lo cual ya era común en los grandes estados americanos y europeos de la época. Como veremos más adelante, en Honduras se vivía una situación semejante a la salvadoreña, lo cual incluso hizo a ambos estados compartir un mismo héroe nacional. Por ello, a inicios de la década de 1880, Francisco Durini fue contratado para materializar los monumentos de distintos héroes centroamericanos y de esta manera su empresa contribuyó en la representación alegórica y pública de los discursos nacionalistas de los estados salvadoreño y hondureño. ${ }^{40} \mathrm{~A}$ continuación nos dedicaremos a uno de los monumentos más relevantes contratados con Durini, por medio del cual, argumentamos, el europeo se integró con éxito al mercado artístico salvadoreño.

35 López, "Poder central y poder local en la construcción del Estado en El Salvador, 1840 1890”, pp. 56-64; Taracena, “Liberalismo y poder político en Centroamérica (1870-1929)”, pp. 187-188.

36 López, “El proyecto liberal de nación en El Salvador (1876-1932)”, p. 90.

37 López, “Inventando tradiciones y héroes nacionales: El Salvador (1858-1930)”, p. 5.

38 “Entusiasmo Patriótico”, Diario Oficial, San Salvador, 14 de septiembre de 1875, p. 1.

39 López, “Inventando tradiciones y héroes nacionales: El Salvador (1858-1930)”, pp. 2-5.

40 Ibíd., p. 6. 


\section{MONUMENTO A FRANCISCO MORAZÁN (1880-1882)}

El primer héroe en ser inmortalizado con un monumento por parte del Estado salvadoreño fue el político y militar hondureño Francisco Morazán Quezada (1792-1842). En conformidad con el historiador salvadoreño Carlos Gregorio López Bernal, el culto estatal salvadoreño a Francisco Morazán se remonta a la década de 1840, pero su mayor desarrollo se dio en la segunda mitad del siglo XIX, siendo el monumento de 1882 una muestra del nivel de oficialización entonces alcanzada por la figura de dicho político hondureño. ${ }^{41}$ No obstante, según López:

Puede afirmarse que hacia 1882, aunque el poder estatal ya estaba bastante consolidado y el proyecto nacional oficial había tomado fuerza, aún persistía una añoranza de la unión centroamericana, situación incompatible con un auténtico sentimiento nacionalista, una de cuyas características es ser marcadamente excluyente de cualquier forma de identidad que pueda minar la lealtad de los individuos hacia su nación. ${ }^{42}$

En otras palabras, dicho proyecto nacionalista transitaba entre la formación de la identidad del Estado nacional salvadoreño y la exaltación del unionismo centroamericano, lo cual generaba una ambigüedad discursiva. En conformidad con López, esto se debía a la constante duda de las autoridades salvadoreñas sobre la viabilidad de El Salvador como nación y a su recelo respecto del posible funcionamiento de una nueva república centroamericana. ${ }^{43}$ Por ello, las élites gobernantes se sirvieron de la figura de Francisco Morazán, ya que les permitía aglutinar los valores patrióticos, republicanos, progresistas y unionistas centroamericanos, los cuales pretendían inculcar en la ciudadanía salvadoreña. ${ }^{44}$

Debido a lo anterior, el proyecto del monumento a Morazán se complementó con la creación de una plaza para la congregación del pueblo alrededor de la imagen de aquel caudillo de la extinta República Federal de Centro América (1824-1839). Rafael Zaldívar contrató a Francisco Durini para producir dicho monumento, pero no conocemos los detalles del contrato. El suizo-italiano diseñó el monumento en 1880 y las piezas marmóreas están fechadas en 1881, pero por motivos desconocidos no fue sino hasta 1882 que éste se inauguró. ${ }^{45}$ Debe señalarse que, aunque Durini diseñó el monumento,

López, "El proyecto liberal de nación en El Salvador (1876-1932)”, p. 90. 
las piezas que lo conforman fueron producidas en Europa por los escultores romanos Marrini y Macaguaní. ${ }^{46}$

Como ya mencionamos, además del monumento, el Estado salvadoreño construyó una plaza para erigir el monumento y enaltecer la figura de Morazán. En el número del Diario Oficial salvadoreño correspondiente al 2 de septiembre de 1880, se argumentó la necesidad de la plaza de la siguiente manera:

Sería mejor colocar un monumento de esta naturaleza en una plaza pública central (...) lo cual contribuiría además a embellecer la capital de la República y será el primer monumento en su género que dará una prueba de nuestro adelanto social y de los patrióticos esfuerzos del país por honrar la memoria de sus grandes hombres. ${ }^{47}$

A esta idea se añade lo escrito en la edición del 8 de septiembre de 1880 del Diario Oficial, en la sección "Grato Público", donde se explicó: "El nuevo parque llevará el nombre de Morazan [sic], y la estatua de este prohombre será colocada en el centro. [...] Honrar la memoria de los grandes hombres es propio de los Gobiernos y de los pueblos justicieros y agradecidos”. ${ }^{48}$ La inversión estatal en dicha obra pública tenía como intención modificar el paisaje de San Salvador y a la vez promover el culto político a Francisco Morazán, un caudillo del federalismo pretérito y una inspiración para lo que los gobernantes e intelectuales de dicha república estaban entendiendo por progreso y nación.

El monumento (Figura 2) está compuesto, todavía hasta el día de hoy, por una figura de bronce que corresponde a Morazán, situada en el centro y en el punto más alto del conjunto, y por cinco piezas elaboradas en mármol, las cuales representan con alegorías femeninas a las cinco naciones centroamericanas (Guatemala, Honduras, El Salvador, Nicaragua y Costa Rica), mismas que forman parte del pedestal que sostiene a Morazán. Durante su fructífera carrera política, Morazán gobernó la República Federal de Centro América (1830-1834 y 1835-1839) y los estados de Honduras (1827-1829 y 1830), El Salvador (1832 y 1839-1840) y Costa Rica (1842), lo cual inspiró el diseño del monumento referido.

46 "La prensa italiana”, La Paz, Tegucigalpa, 27 de enero de 1883, p. 2.

47 López, "El proyecto liberal de nación en El Salvador (1876-1932)”, p. 197.

48 "Grato Público", Diario Oficial, San Salvador, 8 de septiembre de 1880, p. 750. 


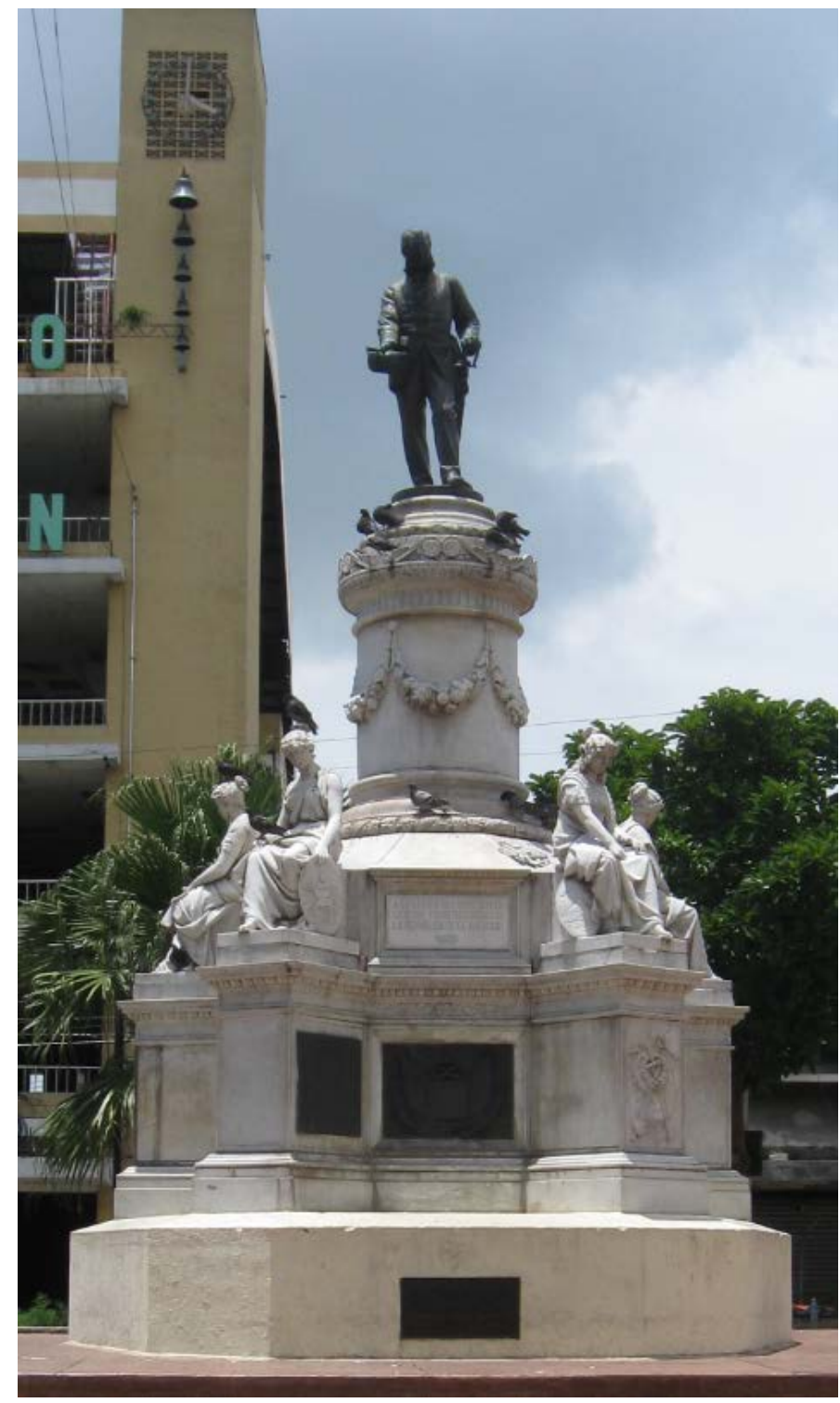

Figura 2. Francisco Durini, Marrini y Macaguaní. Monumento a Francisco Morazán. Piedra, bronce y mármol, 1880-1882, San Salvador, El Salvador. Fuente: Leonardo Santamaría Montero. 
¿Por qué el Estado salvadoreño liberal erigió un monumento con una connotación unionista centroamericana? Además de lo mencionado páginas atrás respecto de la invención de la nacionalidad salvadoreña, debemos señalar que las políticas del presidente Zaldívar estuvieron influenciadas por las de su homólogo guatemalteco, el general Justo Rufino Barrios Auyón (18351885), quien persiguió durante su prolongado mandato (1873-1885) la unión política de Centroamérica. ${ }^{49}$ Similar a lo realizado por Morazán, el general Barrios intervino la política interna de El Salvador y Honduras e incluso pretendió forzar la integración de Nicaragua y Costa Rica a su proyecto unionista. ${ }^{50}$

Mientras que los gobernantes de Nicaragua y Costa Rica rechazaron tajantemente los proyectos unionistas del norte de Centroamérica, el presidente Rafael Zaldívar y Marco Aurelio Soto (1846-1908), presidente de Honduras entre 1876 y 1883, abrazaron la idea y, junto con los intelectuales de sus países, emplearon a la figura histórica de Francisco Morazán para revitalizar el ideal unionista centroamericano. ${ }^{51}$ A pesar de la coincidencia de ideas respecto del proyecto unionista y la capacidad de Guatemala y El Salvador para dirigir tal reunificación, dicho proyecto fracasó, pues ni los guatemaltecos ni los salvadoreños se aventuraron por temor a ser sometidos por sus vecinos. ${ }^{52}$

De este modo, aunque fue hondureño de nacimiento, la figura heroica de Morazán simbolizaba para el gobierno de Zaldívar la nacionalidad centroamericana y los valores positivistas-liberales que caracterizaban a su administración. Como ya adelantamos, tales ideas fueron replicadas por el discurso oficial de la Honduras de Marco Aurelio Soto, lo cual consta en una publicación de La Gaceta oficial de ese país, referente a la presentación pública del monumento salvadoreño a Morazán:

El Gobierno del Salvador, cediendo á [sic] las inspiraciones del más noble patriotismo, é [sic] interpretando el sentimiento nacional del pueblo de aquella República, decretó erigir un monumento destinado á [sic] perpetuar la memoria del General D. Francisco Morazán, del Repúblico más sincero, del batallador más heróico [sic], y de la víctima más ilustre con cuyos hechos egregios se honra la Historia de Centro-América. [...]

El nombre de Francisco Morazán simboliza para nosotros, para todos los que reconocen el verdadero mérito y aspiran al verdadero bien, estos 
principios que infunden el aliento de nuestra vida: libertad, progreso, union [sic] nacional centro-americana. ${ }^{53}$

La inauguración del monumento a Morazán en San Salvador conllevó una gran celebración, en la que diversas figuras políticas representaron a las repúblicas de Honduras, Guatemala y Nicaragua. Recientemente, las relaciones políticas entre El Salvador y Honduras se habían estrechado significativamente, ${ }^{54}$ lo cual dotó al homenaje a Morazán de un gran valor simbólico para sendas naciones, pues dicho caudillo hondureño no sólo gobernó El Salvador, sino que incluso sus restos habían sido sepultados en ese país desde $1849 .{ }^{55}$ Por ello, aunque el monumento y la festividad eran salvadoreñas, la ceremonia inaugural contó con la presencia de altos funcionarios del gobierno hondureño.

Hacia finales de febrero de 1882, vía telegrama, el Gobierno salvadoreño invitó formalmente al Ministro de Relaciones Exteriores de Honduras a asistir a la inauguración del monumento a Morazán. ${ }^{56}$ Ramón Rosa Soto (1848-1893), ministro hondureño, aceptó la invitación de El Salvador y respondió a su homólogo salvadoreño con las siguientes palabras:

Honduras, Señor Ministro, al ver honrada en el Salvador la memoria de uno de sus hijos más ilustres, siente grande y legítima satisfacción, y tiene un motivo más para estar siempre unida, fraternalmente, á [sic] esa noble Nación que va á [sic] dar un testimonio de reconocimiento á [sic] los servicios del abnegado Repúblico [...] [Envío en] nombre de mi Gobierno, al de V. E. la más sincera felicitación porque, como intérprete del sentimiento nacional de ese pueblo generoso, va á [sic] hacer justicia á [sic] los méritos del que supo vivir y sacrificarse por la patria, y, á [sic] dar con ello, una alta prueba de civilización que lo enaltece, y que honra, en gran manera, á [sic] la América Central. ${ }^{57}$

El 15 de marzo de 1882, día de la develación del monumento a Morazán, los políticos salvadoreños y centroamericanos pronunciaron discursos, mismos que fueron publicados en el Diario Oficial salvadoreño durante el mes de marzo. Tales discursos se caracterizaron por la exaltación del monumento

53 “Monumento dedicado á la memoria del ilustre General Francisco Morazán”, La Gaceta, Tegucigalpa, 25 de noviembre de 1882, p. 1.

54 “Nuevos convenios”, La Gaceta, Tegucigalpa, 22 de diciembre de 1880, pp. 1-2.

55 López, “Inventando tradiciones y héroes nacionales: El Salvador (1858-1930)”, p. 3.

56 “Telegramas oficiales relativos á la inauguración del monumento consagrado á la memoria del General Morazán”, La Gaceta, Tegucigalpa, 10 de abril de 1882, p. 2.

57 Ibíd., [Lo agregado es nuestro]. 
como objeto digno de la grandeza del aclamado caudillo unionista. Por ejemplo, en las crónicas de la "fiesta cívica" se narra que en medio del himno nacional salvadoreño:

[...] se descubrió el monumento del gran caudillo, que fue saludado con estrepitosos aplausos, dianas militares y salvas de artillería.

La magestuosa [sic] figura del héroe reflejó por primera vez sobre la muchedumbre los rayos del sol, como para decirle que á [sic] sus plantas deben congregarse los patriotas, siempre que necesiten alentar las esperanzas cívicas $[\ldots] .^{58}$

Estar a los pies del caudillo, una idea que Álvaro Contreras, representante del Ejecutivo Supremo de El Salvador, reforzó:

¡Pueblo generoso del Salvador, pueblo querido de mi corazón! Cuando sea necesario que vuelva á [sic] luchar por las garantías sociales y los derechos del hombre, por la integridad y la independencia de la Patria centroamericana, congrégate al pié de este monumento, pidiendo inspiraciones al Semi-Dios de nuestra Historia. El pondrá su imagen en tu pecho, y triunfarás en todos los grandes lances que te esperan! ${ }^{59}$

Contreras a su vez expresó que:

Estamos en presencia de la personificación en bronce del primer héroe centroamericano.

El cincel del artista ha venido á [sic] inmortalizar la noble imagen del hombre extraordinario que por maravillosa manera supo improbarse el señor de la victoria, el númen [sic] del patriotismo, el genio de la libertad, el inmortal favorito de la gloria. ${ }^{60}$

Éstas y otras muchas palabras relativas al monumento y a su significado se pronunciaron en los fastuosos festejos de aquel día y circularon en los diarios centroamericanos. Con esta efigie se reforzaba entonces el ideal de unión centroamericana compartido por distintas élites salvadoreñas y centroamericanas de la época. Dicho objetivo queda claro, por ejemplo, en la edición del 14 de marzo de 1882 del Diario Oficial, en un texto llamado "Un artículo brillante”, donde se dice: “[...] y hoy que se levanta el primer mo- 
numento á [sic] Morazán, procuremos cumplir con su última voluntad, erigiendo un monumento más grandioso y digno de él: la unión centro americana”. ${ }^{61}$

No obstante, debemos recordar que la heroización de Morazán y su monumento tenían un doble uso discursivo y político por parte del gobierno de El Salvador. Por un lado, la figura de Morazán fue utilizada para fomentar cierto nacionalismo salvadoreño de carácter oficialista, el cual pretendía aglutinar a los pueblos de El Salvador bajo una misma identidad nacional y con ello legitimar a las autoridades del Estado. ${ }^{62}$ Por otro lado, el monumento a Morazán es un síntoma de la añoranza de algunas élites salvadoreñas por la antigua unidad política centroamericana, empero esto nunca dejó de ser un ideal, pues la unificación nunca se llevó a cabo de forma efectiva. ${ }^{63}$

Regresando a Francisco Durini, podemos decir que, con el monumento a Morazán, el comerciante europeo se integró exitosamente al mercado artístico centroamericano y comenzó su contribución estética a los proyectos nacionales de las repúblicas del istmo. Es importante dejar claro que el proyecto nacionalista de estos países no era algo que fuese necesariamente del interés de Durini. De hecho no tenemos conocimiento sobre la postura de Francisco Durini en cuanto al contexto de la región. Por lo tanto, hemos de limitarnos a considerar que la prioridad del comerciante era integrarse al mercado artístico, fundamentalmente el oficialista, ya que generaba una base segura para dar a conocer y expandir su negocio. Prueba de ello es que en 1882, año de la inauguración del monumento salvadoreño a Morazán, Ramón Rosa, la mano derecha del presidente Soto, le encargó a Durini la producción de una serie de estatuas de héroes nacionales hondureños, entre ellas, otro monumento a Morazán. ${ }^{64}$ Ese mismo año, Durini construyó un suntuoso mausoleo a Morazán en el cementerio de San Salvador, lugar donde todavía se encuentran los restos del caudillo unionista. ${ }^{65}$

Ahora bien, ¿qué sabemos de Lorenzo Durini en estos años? ¿Tuvo alguna relación con los proyectos de su hermano en El Salvador?

“Un artículo brillante”, Diario Oficial, El Salvador, 14 de marzo de 1882, p. 259.

López, "Inventando tradiciones y héroes nacionales: El Salvador (1858-1930)”, pp. 8-9.

Ibíd., p. 9.

Rosa y Durini, "Contrata”, pp. 438-439. Cf. Bochichio, "La contribución italiana a la imagen monumental —escultórica y arquitectónica — de la independencia en Honduras”, p. 17; La Gaceta, Tegucigalpa, 27 de agosto de 1882.

Durini, El Salvador Monumental y sus obras hermanas en América, p. 99. 


\section{LORENZO DURINI, OTRAS OBRAS Y POSIBLE DINÁMICA EMPRESARIAL (1882-1883)}

Si bien el contrato para el monumento salvadoreño a Morazán fue firmado por Francisco Durini y en la prensa sólo se mencionó su nombre, hipotetizamos la participación de Lorenzo Durini en dicha empresa, probablemente desde Europa. En una carta remitida por éste desde Tegucigalpa en mayo de 1883 referente a la instalación de los monumentos hondureños, el suizoitaliano indicó que entonces moraba en El Salvador, ${ }^{66}$ donde, se supone, residía su hermano. Debe señalarse que dicha carta, aunque firmada por Lorenzo Durini, presenta un sello con la siguiente información: "Francisco A. Durini. Escultor y Negociante en marmoles [sic]. Genova [sic]. Italia. San Salvador. Centro America [sic]" (Figura 3) ${ }^{67}$ Considerando que Francisco Durini se encontraba en Génova en ese momento, es probable que su hermano se estableciese en San Salvador para representarlo allí; de la misma manera, posiblemente mientras Francisco Durini negociaba en Centroamérica, Lorenzo Durini coordinaba en Europa los encargos de su hermano (por ejemplo: las partes del monumento salvadoreño a Morazán). ${ }^{68}$

Quizás Lorenzo Durini se trasladó a El Salvador para encargarse de las obras contratadas a su hermano después de la conclusión del monumento a Morazán. Según los resultados de esta investigación, podemos asegurar que Lorenzo Durini tuvo una mayor participación en los trabajos arquitectónicos de la empresa familiar, lo cual podría explicar su presencia en San Salvador hacia 1882-1883, pues entonces Francisco Durini construía: "un Matadero, un Palacio Presidencial y otros más que está estudiando y proyectando". ${ }^{69}$

Entonces, aparentemente Lorenzo Durini estaba en El Salvador mientras su hermano Francisco negociaba en Honduras, y luego Lorenzo se trasladó a Honduras para que su hermano viajara a Génova.

Concentrándonos en la información aportada por el sello de Francisco Durini de 1883 (Figura 3), ${ }^{70}$ es menester subrayar las locaciones indicadas por dicha inscripción: Génova (Italia) y San Salvador (Centroamérica). En conformidad con tal información, parece que San Salvador era el centro de operaciones en Centroamérica de Durini, mientras que probablemente la empresa contaba con socios en el puerto italiano de Génova; además, debe

66 “Carta de Lorenzo Durini al Ministro de Fomento de la República de Honduras”, Honduras, 30 de mayo de 1883, Archivo Nacional de Honduras (en adelante: ANH), Fomento, carpeta 20, legajo 32, f. 49.

67 Ibíd.

68 Capello, City at the Center of the World: Space, History, and Modernity in Quito, p. 122.

69 “La prensa italiana”, La Paz, Tegucigalpa, 27 de enero de 1883, p. 2.

70 “Carta de Lorenzo Durini al Ministro de Fomento de la República de Honduras”, Honduras, 30 de mayo de 1883, ANH, Fomento, carpeta 20, legajo 32, f. 49. 
considerarse a Lorenzo Durini, quien supuestamente vivía en Tremona. ${ }^{71}$ En todo caso, la dinámica artístico-comercial de los Durini se caracterizó desde sus primeros años por la movilidad de ambos hermanos entre América y Europa, la cual respondió al éxito comercial, a la naturaleza de los encargos y tal vez a asuntos de índole familiar.

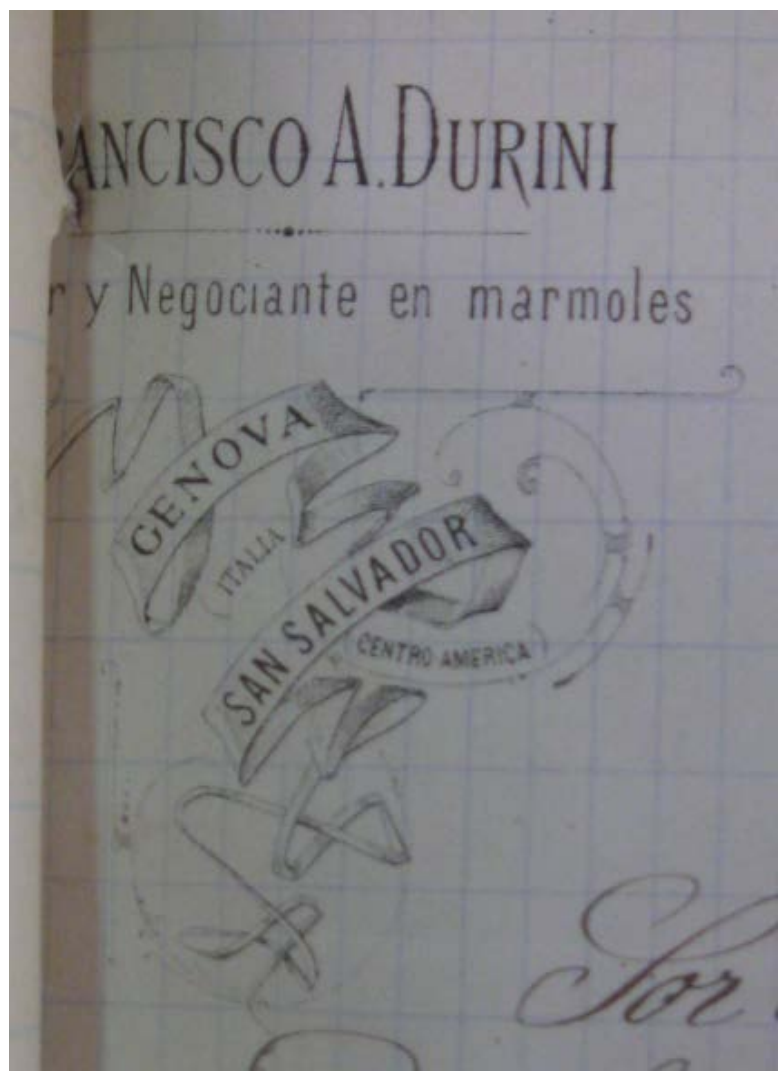

Figura 3. Sello de Francisco A. Durini. 1883.

Fuente: Archivo Nacional de Honduras.

71 Se puede hipotetizar que, entre los motivos por los que a Francisco Durini le correspondió viajar primero a Centroamérica, y no a su hermano Lorenzo, estaría el hecho de que, a diferencia de su hermano, Francisco aún no había formado una familia, condición que complicaría mucho más el ofertar servicios artísticos de forma paralela a asentar el negocio en El Salvador. 


\section{HONDURAS. FRANCISCO DURINI Y LORENZO DURINI(1882-1883): MONUMENTOS A FRANCISCO MORAZÁN, JOSÉ CECILIO DEL VALLE, JOSÉ TRINIDAD REYES, JOSÉ TRINIDAD CABAÑAS Y MÁXIMOJEREZ}

Después de El Salvador, Honduras es el segundo mercado artístico en el cual tuvo éxito Francisco Durini. Así como en el caso salvadoreño, Durini accedió a contratos con el Estado hondureño para producir los monumentos a sus héroes nacionales. Consecuentemente, su fama aumentó en sendos países y en Europa, lo cual cimentó las bases de su lucrativa empresa artísticocomercial. Asimismo, debe señalarse que hacia 1883 se cuenta con mayor evidencia de la participación de Lorenzo Durini en los negocios de su hermano en tierras americanas.

Tal como mencionamos líneas atrás, las políticas liberales de la administración del doctor Marco Aurelio Soto, e incluso su designación como presidente de la República de Honduras, estuvieron vinculadas con la voluntad del general Justo Rufino Barrios. ${ }^{72}$ Soto ejerció el poder junto a su cuñado, Ramón Rosa, quien contribuyó —entre otras cosas - como ideólogo de la reforma al Estado hondureño. ${ }^{73}$ A mediados de 1880, año del decreto del presidente salvadoreño Rafael Zaldívar para erigir el monumento a Morazán, el doctor Rosa abanderó el unionismo centroamericano desde el oficialismo hondureño. ${ }^{74}$ Lo anterior explica el seguimiento dado por la prensa estatal hondureña a la develación del monumento salvadoreño a Morazán (1882) y la participación de Rosa en dicha actividad.

En tal contexto político, y probablemente a causa del mismo, Francisco Durini llegó a Honduras a comerciar sus productos, los cuales contribuyeron en la construcción visual de esa república centroamericana. No se tiene claro cómo se vinculó Durini con el gobierno de Soto y Rosa ni por qué fue elegido para encargarse de los monumentos hondureños. Proponemos la hipótesis de que la relación entre Durini y los gobernantes de Honduras pudo desarrollarse por motivo de la inauguración del monumento salvadoreño a Morazán, pues el contrato se celebró meses después de aquella festividad y a instancias de Rosa. Consideramos estos trabajos las primeras obras estatales colocadas por Francisco Durini en Honduras y posiblemente sus primeros contratos en ese país. ${ }^{75}$

\footnotetext{
Taracena, “Liberalismo y poder político en Centroamérica (1870-1929)”, p. 190.

Ibíd., pp. 190-193.

7 Ibíd., p. 193.

75 Tenemos conocimiento de otras piezas encargadas a Francisco Durini en esa misma época, pero no tenemos clara su fecha de contratación ni tenemos mayor información al respecto de ellas. Por ejemplo, en el diario La Paz del 27 de enero de 1883 se publicaron extractos de una carta que dirige Francisco Durini al Presidente Soto, en donde se menciona que el 25
} 


\section{MONUMENTOS A LOS HÉROES NACIONALES HONDUREÑOS (1882-1883)}

Hoy la patria hondureña, aun velada por las sombras del dolor, y rebosando de los más nobles sentimientos, por medio de su Gobierno, consagra un elocuentísimo testimonio público de sus imperecederos recuerdos y de su inmensa gratitud á [sic] sus hijos predilectos: Á [sic] FRANCISCO MORAZÁN, Á [sic] JOSÉ CECILIO DEL VALLE, Á [sic] JOSÉ TRINIDAD REYES Y Á [sic] TRINIDAD CABAÑAS. ${ }^{76}$

Con estas palabras se hacía referencia el 27 de agosto de 1882 a los monumentos que serían erigidos en honor a algunas de las figuras históricas más importantes de la política hondureña y centroamericana. Como ya fue anotado, la inauguración del monumento a Morazán en San Salvador reunió a diversas figuras políticas, las cuales estaban en representación de Honduras, Guatemala y Nicaragua. De modo que el proyecto salvadoreño fue para Francisco Durini una suerte de vitrina internacional.

En 1882, año de inauguración del monumento en El Salvador, Ramón Rosa, Ministro General de Honduras, en representación del presidente Marco Aurelio Soto, le encargó a Durini un grupo de estatuas que representasen a los siguientes héroes hondureños: Francisco Morazán, el intelectual José Cecilio del Valle (1780-1834), el sacerdote José Trinidad Reyes y Sevilla (1897-1855) y el militar José Trinidad Cabañas Fiallos (1805-1871). Las piezas se colocarían en 1883 y serían inauguradas el 30 de noviembre de ese año. ${ }^{77}$

El contrato fue firmado el 29 de julio de $1882 .{ }^{78}$ Francisco Durini debía proveer al gobierno hondureño una estatua ecuestre de Morazán, la cual fue ejecutada por el escultor francés Léopold Morice (1846-1919) (Figura 4); ${ }^{79}$

del mismo mes, el contratista enviaba desde un vapor que salió de Barcelona "[...] las cuatro estaciones [...]". Puede que se esté refiriendo a cuatro piezas que representan a las estaciones que se ubican actualmente en la Plaza Central de Tegucigalpa. En el mismo documento se hace mención de otros objetos relativos a lo que debía ornamentar a los cuatro monumentos, además "[...] 20 macetas para adorno de las plazas; 4 jarrones para poner arriba de la puerta principal del Hospital; los dos letreros para aponer arriba también de las dos puertas del mismo edificio; todos los materiales para la colocación; un tablero para la mesa de autopsia: libritos, fotografías, folitipias para repartir el día de la inauguración [...]”. “Extractos”, La Paz, Tegucigalpa, 27 de enero de 1883, p. 4.

76 La Gaceta, Tegucigalpa, 27 de agosto de 1882, p. 3.

77 En conformidad con Bochiccio, la inauguración se daría en ocasión a la nominación al Presidente de la República del General Luis Bográn (1849-1895): Bochicchio, “La contribución italiana a la imagen monumental —escultórica y arquitectónica — de la independencia en Honduras”, p. 17.

78 Rosa y Durini, “Contrata”, pp. 438-439.

79 Bochiccio afirma con seguridad que la escultura de Morazán en realidad no representa al caudillo, sino a un mariscal segundo de Napoleón. Esto abre la hipótesis de que la estatua ya 


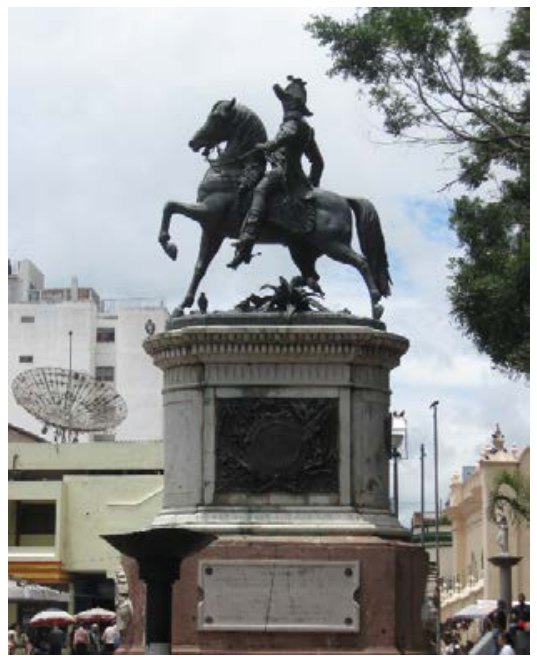

Figura 4. Francisco Durini, Léopold Morice y Canessa, Monumento a Francisco Morazán (1882-1883), piedra, mármol y bronce, Tegucigalpa, Honduras.

Fuente: Leonardo Santamaría Montero.

estuviese realizada por el escultor antes de ser solicitada por Francisco Durini para el contrato hondureño, y que tal vez estuviese destinada anteriormente a otro conjunto escultórico que no sucedió. Bochicchio, "La contribución italiana a la imagen monumental —escultórica y arquitectónica- de la independencia en Honduras”, p. 17.

Si bien esta teoría es plausible, es también claro que contamos con varias fuentes que nos hablan de la realización particular del monumento por parte de Morice, como si la pieza estuviese en proceso de creación. Por ejemplo, en el semanario La República, de El Salvador, en su edición del 21 de diciembre de 1882, tenemos noticias del proyecto de Francisco Durini en El Salvador: “Según 'La Paz' de Tegucigalpa, los trabajos del monumento de Morazán se están realizando en Italia con rapidez y cuidadoso esmero, por el escultor Leopoldo Morice. El contratista señor Durini escribe de Génova, asegurando que la obra será espléndida”. "Según 'La Paz' de Tegucigalpa”, La República, San Salvador, 21 de diciembre de 1882, p. 5.

El tema del tiempo en que se debían entregar las obras también es uno de los motivos para pensar en una escultura ya existente por parte de Morice, ya que ésta era la pieza más grande de todo el contrato, al ser un monumento ecuestre. Sin embargo, en el número del diario La Paz, publicado el 27 de enero de 1883, se comenta lo que dice el diario genovés La Lombardía sobre los trabajos que está elaborando Francisco Durini, y nos dice que "[...] para economizar tiempo, debió confiar al inteligente escultor Don Leopoldo Morice [...] la ejecución de la estátua ecuestre de Morazán, la cual será fundida en bronce [...]”. Entonces, se sigue hablando del trabajo de Morazán como uno sin realizar aún, y que el escultor lo iba a hacer particularmente para el contrato de Francisco Durini con Honduras. "La prensa italiana”, La Paz, Tegucigalpa, 27 de enero de 1883, p. 1.

Estas fuentes provocan que el tema de la autenticidad de la Estatua de Morazán pueda seguir siendo objeto de debate. 
una estatua de cuerpo completo de del Valle, producida por un escultor genovés de apellido Bacigalupo (Figura 5); y los bustos de José Trinidad Reyes Figura 6) y José Trinidad Cabañas (Figura 7), obras de un escultor genovés de apellido Beltramí. Un artista de apellido Canessa, también genovés, se encargó de la parte arquitectónica de los cuatro monumentos. ${ }^{80}$

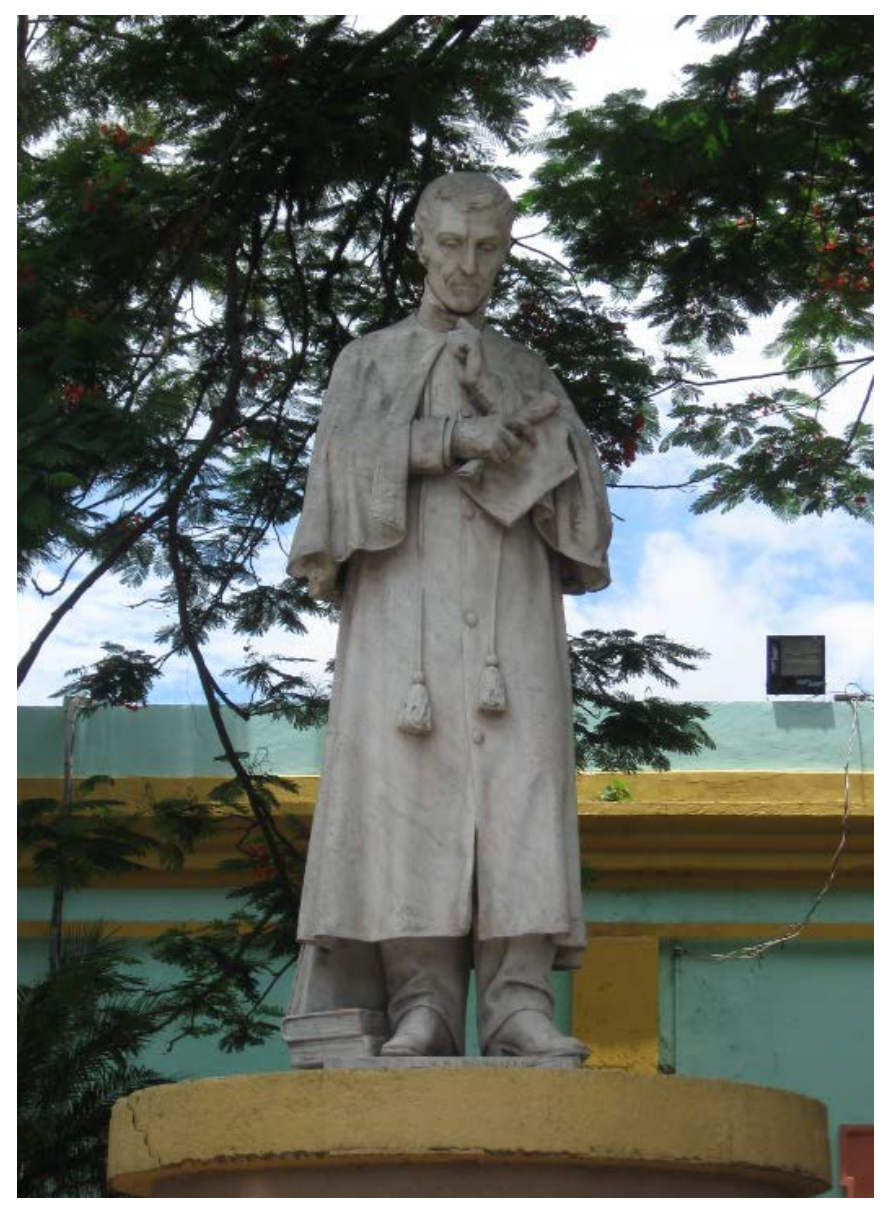

Figura 5. Francisco Durini, G. B. Bacigalupo y Canessa, Monumento a José Cecilio del Valle (1882-1883), mármol y piedra, Tegucigalpa, Honduras. Fuente: Leonardo Santamaría Montero. 


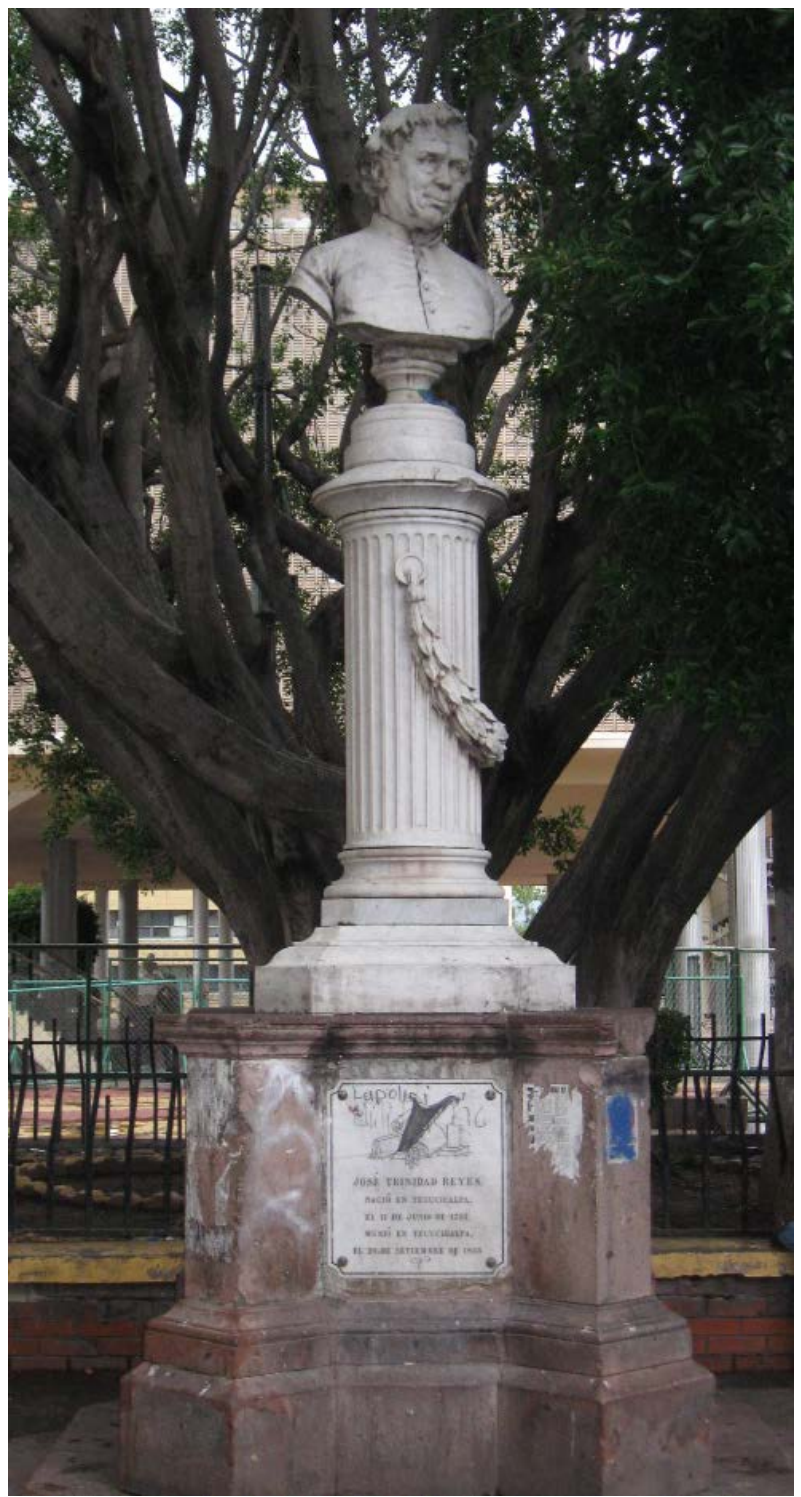

Figura 6. Francisco Durini, Beltramí y Canessa, Monumento a José Trinidad Reyes (1882-1883), mármol y piedra, Tegucigalpa, Honduras. Fuente: Leonardo Santamaría Montero. 


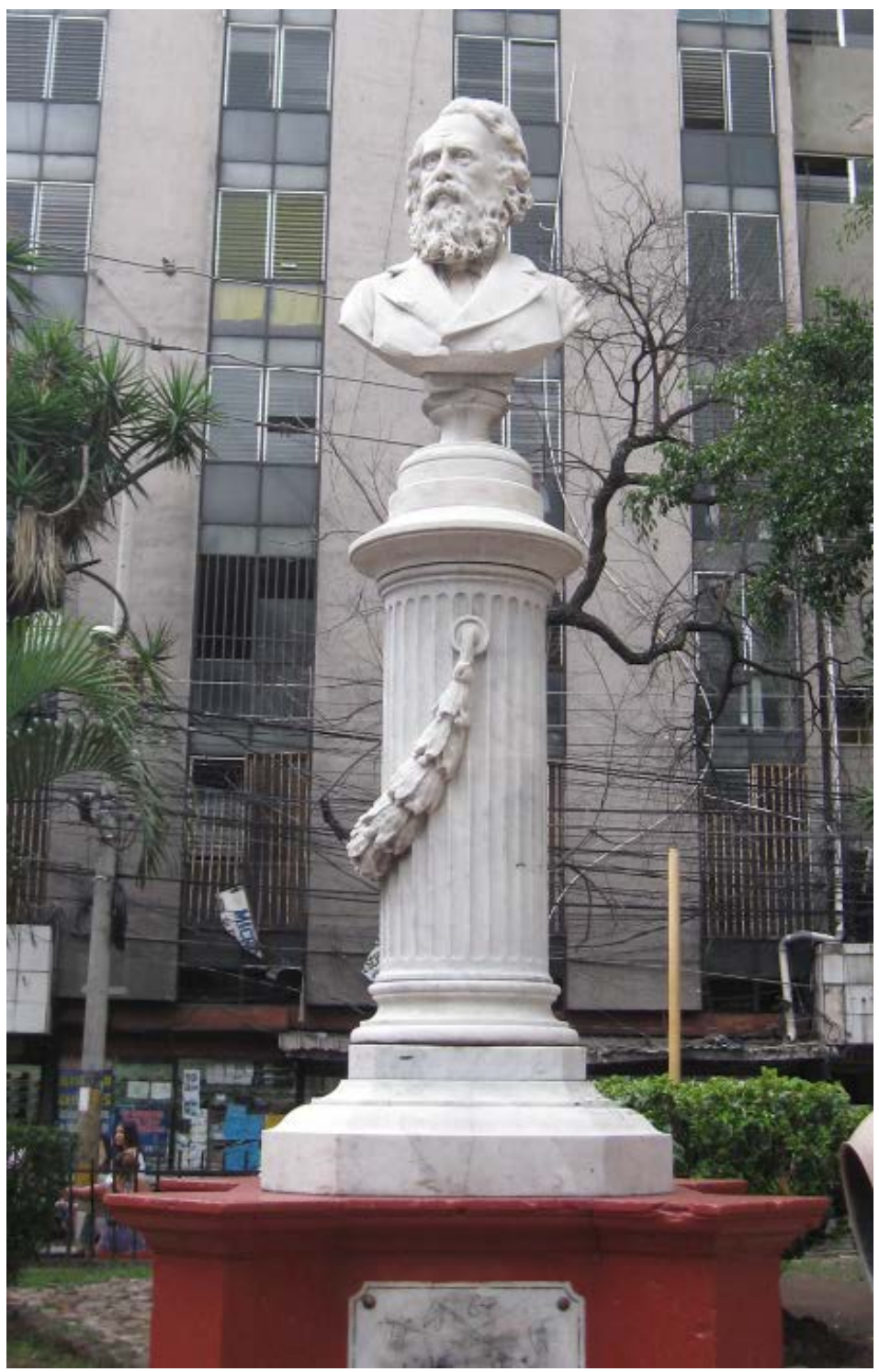

Figura 7. Francisco Durini, Beltramí y Canessa. Monumento a José Trinidad Cabañas. Mármol y piedra, (1882-1883), Tegucigalpa, Honduras. Fuente: Leonardo Santamaría Montero. 
Los motivos de la selección de dichas figuras eran claros. ${ }^{81}$ Ponemos de primer ejemplo a Morazán, cuyo sentimiento hondureño respecto del caudillo centroamericano es análogo al salvadoreño. Como el símbolo unionista republicano-federal por excelencia, Morazán reflejó los “[...] principios que infunden el aliento de nuestra vida: LIBERTAD, PROGRESO, UNION [sic] NACIONAL CENTRO-AMERICANA." ${ }^{82}$ Dicho proyecto era un deber por parte de cualquier pueblo culto, idea señalada por el presidente Soto en su decreto del 27 de agosto de 1882, ya que éste tenía que:

[...] honrar la memoria de sus grandes hombres [...] el BENEMÉRITO GENERAL DON FRANCISCO MORAZÁN fue, para el pueblo hondureño, el heróico [sic] sostenedor de sus derechos, y el más ilustre Representante del Gobierno Republicano y por la Unión Nacional de Centro América [...]. ${ }^{83}$

El carácter unionista es similar al dirigirnos a los motivos del busto de mármol de Trinidad Cabañas, ya que él “[...] formó un alto ejemplo de moralidad política, de valor heroico y de lealtad militar; y que fue el soldado veterano é incorruptible de la noble causa de la Nacionalidad de CentroAmérica [...]" ${ }^{84}$ En el caso de José Cecilio del Valle, las razones varían hacia el campo cultural, al haber sido éste un "[...] Ciudadano eminente cuyas obras honran a las letras centro-americanas; y que por su ciencia, por sus virtudes, y por los servicios que [ha] puesto a la patria, es acreedor a la gratitud nacional [...]". ${ }^{85}$ Estas causas son compatibles con las dadas para el busto de Trinidad Reyes, quien "[...] con su ciencia, con sus producciones poéticas, y con su buen consejo y caridad, supo dar honra á [sic] la Patria y hacerle grandes beneficios [...]". ${ }^{86}$

Ahora bien, aunque el conjunto de los monumentos hondureños aluden al ideal de unión centroamericana, lo cual fue enunciado en distintas ocasiones

Ya desde antes conocemos tributos que se les estaban rindiendo a personajes como Morazán y del Valle. En el decreto emitido por Marco Aurelio Soto el 22 de diciembre de 1881, publicado el 24 de diciembre del mismo año en La Gaceta, se solicita "[....] escribirse y publicarse una Biografía completa del General Morazán, y hacerse una edición de las obras del Señor Valle, con la Biografía del autor [...]”; dichas tareas serían realizadas por Ramón Rosa. "Acuerdo en que se comisiona al Doctor Don Ramón Rosa para que escriba la biografía del general Don Francisco Morazán, y para que publique los manuscritos que posee de las obra del sabio Don José Cecilio del Valle”. La Gaceta, Tegucigalpa, 24 de diciembre de 1881, p. 3.

"Monumento dedicado á la memoria del ilustre General Francisco Morazán”, La Gaceta, Tegucigalpa, 25 de febrero de 1882, p. 1.

${ }^{84}$ Rosa, "Decreto", p. 438.

85 “Guerra”, La Gaceta, Tegucigalpa, 27 de agosto de 1882, p. 3.

86 Ibíd. 
por las autoridades gubernamentales, no podemos obviar la relación de dicho proyecto con la invención del discurso nacional oficialista de Honduras. De este modo, a diferencia del gobierno salvadoreño y su culto a un héroe hondureño (entendido como centroamericano), los jerarcas de Honduras trataron de construir su identidad nacional utilizando la figura de cuatro héroes nacidos en su país. Por ello, las efigies de esos héroes fueron inmortalizadas en bronce y mármol; igual al caso del monumento salvadoreño a Morazán, lo anterior fue posible gracias a la empresa transatlántica de los hermanos Durini.

\section{LA PRENSA ITALIANA COMENTA LAS OBRAS DE FRANCISCO DURINI (1882)}

El proyecto de los monumentos hondureños llegó a conocimiento de algunos periódicos italianos, los cuales publicaron en 1882 notas referentes a Francisco Durini y sus negocios en Centroamérica. En la edición del 27 de enero de 1883 del diario hondureño $\mathrm{La} P a z$, se aseguraba que la prensa italiana tenía "[...] particular interés de los artísticos monumentos que, por decreto del Gobierno de Honduras, van á [sic] levantarse para honrar la memoria de nuestros más ilustres hombres". ${ }^{87}$ En esa misma publicación, La Paz reprodujo traducciones al español de artículos publicados en 1882 por periódicos de Génova, Roma y Florencia. ${ }^{88}$

Además de aportar información valiosa sobre los artistas europeos involucrados en las obras comisionadas a Durini por el Estado hondureño, los artículos periodísticos italianos clarifican parcialmente los movimientos de Durini hacia noviembre de 1882. Por ejemplo, en una nota publicada el 7 de noviembre de 1882 en el periódico genovés La Lombardía, se informó que desde hacía pocos días Durini estaba en Génova comisionando obras para el Gobierno de Honduras, las cuales, suponemos, eran los monumentos antes comentados. ${ }^{89}$ En términos generales, en los tres artículos periodísticos se exaltó la gesta artístico-comercial de Durini y la trascendencia de su trabajo como puente entre el arte italiano y el mercado centroamericano. ${ }^{90}$ Muestra de ello son algunas de las palabras publicadas en noviembre de 1882 por el Gacetino Artístico Literario de Florencia:

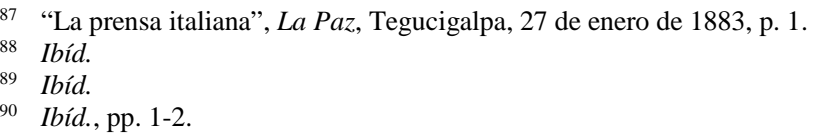


Francisco A. Durini es el nombre de un jóven [sic] artista genovés, el cual honra el arte italiano en aquellas lejanas regiones de las Repúblicas CentroAmericanas, y primero entre todos hace esfuerzos para su desarrollo en aquellas poblaciones en donde las bellas artes han sido hasta ahora poco ó [sic] nada conocidas. [...]

Honor, pues, á [sic] quien, á [sic] más de esforzarse asiduamente por el incremento de la arte italiano [sic] en aquellas lejanas tierras, procura también á [sic] nuestros jóvenes artistas el medio de hacerse honor y de superar los primeros obstáculos de la vida artísticas que son los más difíciles. [...]

Así la fama de los italianos en materia de arte hará repercutir de hecho su clarín también entre los pequeños pero inteligentes Estados de CentroAmérica. ${ }^{91}$

En primer lugar llama la atención la italianización de Durini, pues diversas fuentes legales nos indican que era suizo, no italiano. Como señalamos páginas atrás, los Durini nacieron en Suiza y pasaron su infancia en Perú; no fue hasta su adolescencia que, se supone, viajaron a Génova para formarse como escultores y arquitectos. Considerando lo anterior, es probable que Durini se identificara como genovés por motivos comerciales, pues Génova gozaba de mayor prestigio artístico que Tremona, su verdadera ciudad natal. Además, aunque Durini no fuese italiano, sus negocios se caracterizaron por la venta de obras y materiales italianos, lo cual les confería un gran valor material y simbólico. Entonces, tal y como lo expresan las palabras arriba citadas, Durini representaba en Centroamérica al arte italiano y a la vez fomentaba su consumo entre los ciudadanos centroamericanos.

Finalmente, debe resaltarse la publicación de las traducciones de las notas periodísticas italianas en La Paz de Honduras pues, además de justificar la calidad artística de los monumentos ante los lectores hondureños, tales artículos promocionaban los servicios de Francisco Durini. Del mismo modo, puede suponerse que la publicación de esos artículos en Roma, Génova y Florencia podía apuntar a difundir el nombre de Durini en Italia y a potenciar el surgimiento de nuevos socios comerciales en Europa.

\section{Monumento al General Máximo Jerez (1883)}

Durante el proceso de producción de los monumentos a los héroes hondureños, el Gobierno de Honduras decidió obsequiarle a "[...] los nacionalistas de Nicaragua [...]” una estatua del General Máximo Jerez Tellería (18181881), político y militar nicaragüense afiliado al unionismo centroameri- 


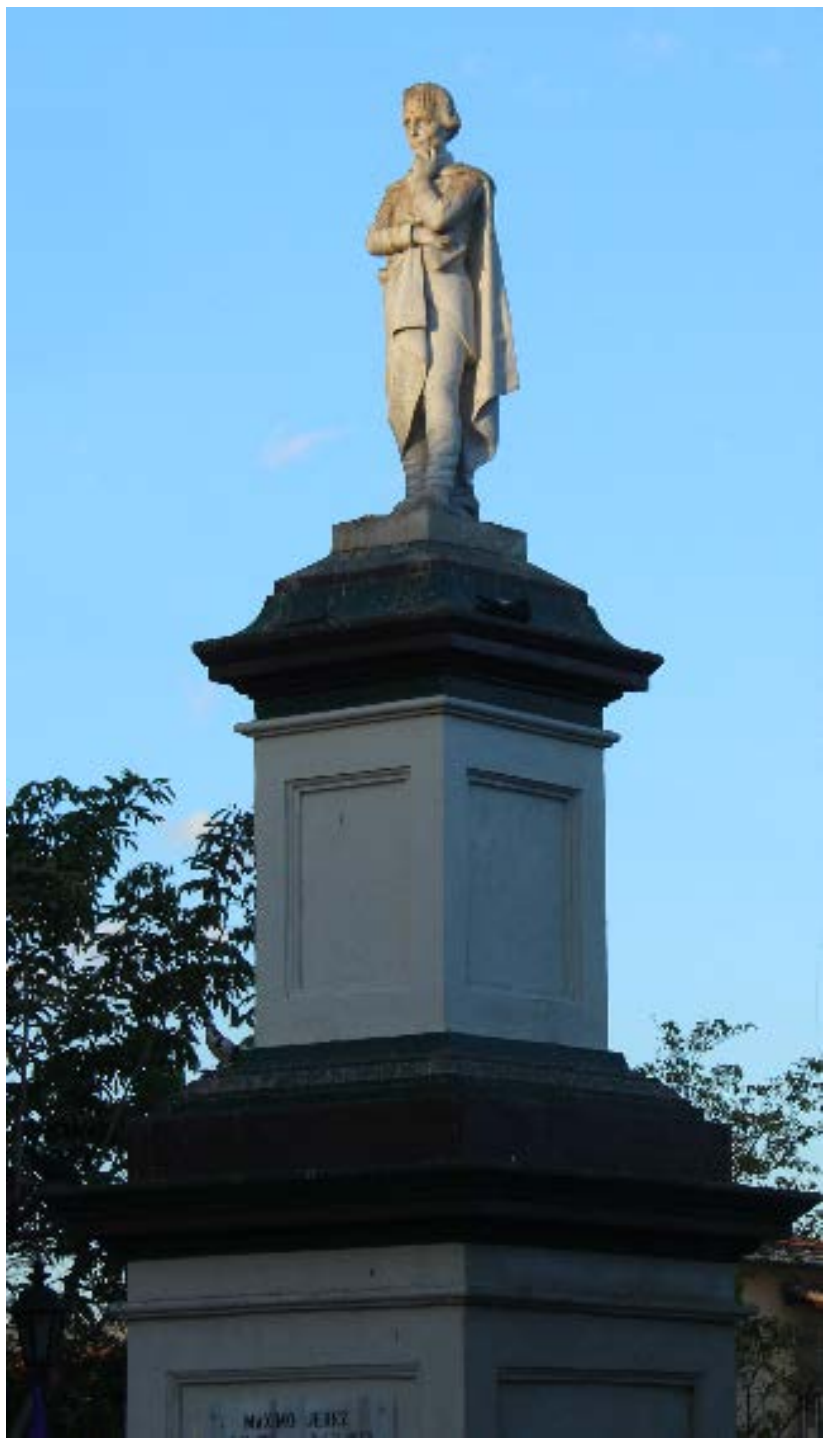

Figura 8. Francisco Durini, Monumento a Máximo Jerez (1883), mármol y piedra, León, Nicaragua.

Fuente: Mauricio Oviedo Salazar. 
cano. ${ }^{92}$ El acuerdo tiene fecha de enero 28 de 1883, y muestra, en breves palabras, la solicitud que Pastor Valle, comisionado del Club Liberal de León, hizo al Gobierno de Honduras para que contribuyera en la elaboración de un monumento que honrase "[...] la memoria del patriota centroamericano [...]" ${ }^{93}$ En respuesta, el Gobierno hondureño manifestó su “[...] propósito de cooperar á [sic] que se haga justicia y se honre el verdadero mérito de los centro-americanos que han sabido sostener con lealtad y firmeza elevadas y generosas ideas [...]". ${ }^{94}$

En el mismo acuerdo se encomienda la producción de la estatua a Francisco Durini. ${ }^{95}$ El contrato se firmó el 6 de mayo entre Enrique Gutiérrez, Secretario de Estado en los Despachos de Relaciones Exteriores, Fomento y Guerra, en representación del Gobierno de la República de Honduras, y el artista-comerciante europeo, en el que Durini “[...] se compromete á [sic] hacer construir en Italia, una estátua [sic] del General Don Máximo Jerez [...]" y que "[...] se compromete á [sic] entregar dicha estátua [sic] en el puerto de Corinto, República de Nicaragua [...]”, a finales de enero de 1884. ${ }^{96}$ Dicha obra se encuentra actualmente en Nicaragua, en la plaza frente a la Catedral de León (Figura 8).

\section{LORENZO DURINI ENTRE EL SALVADOR, HONDURAS Y EUROPA (1883)}

La estancia de Francisco Durini en Génova podría explicar la presencia de su hermano en Honduras.97 Quizás el viaje de Francisco Durini a Génova para dirigir la producción de los monumentos se haya tardado más de lo esperado, ya que, gracias a una carta escrita por Lorenzo Durini al Ministro de Fomento de Honduras el 30 de mayo de 1883, sabemos que quien instalaría las piezas en el territorio centroamericano sería él. En dicha carta se indica que Lorenzo Durini estaba en Honduras desde el 29 de marzo de 1883 con la tarea de instalar los monumentos, pero que éstos aún no habían llegado. Durini manifestó que estaba enfermo, y que por no haber llegado aún las

92 “Acuerdo por el que se encarga la estatua del General Jerez, para obsequiarla á los nacionalistas de Nicaragua”, La Gaceta, Tegucigalpa, 28 de enero de 1883, p. 2.

93 Ibíd.

94 Ibíd.

95 Ibíd

96 "Contrata celebrada con Don Francisco A. Durini, para la construcción de la estátua del General Don Máximo Jerez”, La Gaceta, Tegucigalpa, 18 de septiembre de 1883, p. 1.

97 "Carta de Lorenzo Durini al Ministro de Fomento de la República de Honduras", Honduras, 30 de mayo de 1883, ANH, Fomento, carpeta 20, legajo 32, f. 49; "La prensa italiana”, $L a$ Paz, Tegucigalpa, 27 de enero de 1883, p. 1. 
piezas le solicitaba al Ministro hondureño el permiso para retirarse momentáneamente a su casa en El Salvador. ${ }^{98}$ Vemos entonces cómo Lorenzo Durini procuraba el cumplimiento del contrato de su hermano con el gobierno hondureño. ${ }^{99}$

La estadía de Lorenzo Durini en El Salvador en 1883 suscita interrogantes relativas al sitio en donde vivían oficialmente Durini y su familia. Si bien no podemos afirmarlo con seguridad, quizás su residencia en territorio centroamericano era temporal. Recordemos que, según Capello, ${ }^{100}$ Lorenzo Durini y su esposa decidieron irse de Perú después de su matrimonio (en abril de 1879), para asentarse luego en Tremona, donde tuvieron a sus tres hijos entre 1880 y 1889. Esto nos permite hipotetizar que Lorenzo Durini participó en los negocios de su hermano, en ocasiones, representándolo por períodos de tiempo en Centroamérica. Sin embargo, la evidencia documental apunta a que hacia 1883 la residencia definitiva de Lorenzo Durini se mantenía todavía en Europa, mientras que parece que su hermano sí residía en San Salvador. A inicios de 1883 Francisco Durini delegó a su hermano las responsabilidades de representarlo ante el gobierno hondureño durante su ausencia del país y además le encargó recibir e instalar lo que él le enviaba desde Génova. Podemos fortalecer la hipótesis que propone una estadía temporal de Lorenzo Durini en Centroamérica gracias a la información indicada por él mismo en el siguiente aviso publicado en La Gaceta de Honduras hacia el final de 1883:

Debiendo marchar á $[s i c]$ Europa al terminarse el contrato que mi hermano Francisco A. Durini celebró con el Supremo Gobierno, ofrezco al público encargarme de los pedidos que se me hagan, de toda clase de obras de mármol como Mausoleos, lápidas, tableros para muebles, jarrones, estátuas [sic], \&. \&., [sic] por ser este el ramo de mi profesión.

También atenderé con esmero los pedidos de vinos, licores, comestibles y abarrotes, en cuyo ramo poseo los conocimientos necesarios para satisfacer á [sic] mis comitentes. ${ }^{101}$

En dicho anuncio, Lorenzo Durini justifica su estadía en Centroamérica con el cumplimiento del contrato celebrado entre su hermano y el gobierno

98 En efecto, el mismo 30 de mayo el Gobierno hondureño concedió a Lorenzo Durini el permiso solicitado, mientras se esperaba a que llegasen los monumentos. "Acuerdo en que se concede licencia á Don Lorenzo Durini”, La Gaceta, Tegucigalpa, 14 de agosto de 1883, p. 4.

99 "Carta de Lorenzo Durini al Ministro de Fomento de la República de Honduras”, Honduras, 30 de mayo de 1883, ANH, Fomento, carpeta 20, legajo 32, f. 49

100 Capello, City at the Center of the World: Space, History, and Modernity in Quito, p. 122.

101 “Aviso”, La Gaceta, Tegucigalpa, 9 de diciembre de 1883, p. 4. 
hondureño. Además, señaló que remitía tal aviso desde la casa de "Don Manuel Sequeiros" 102 donde, presumimos, residía temporalmente en Tegucigalpa. ${ }^{103}$ Si se considera tal información y lo indicado en el sello de Francisco Durini de 1883, se deduce que el menor de los Durini residía permanentemente en Centroamérica (El Salvador), mientras que Lorenzo Durini vivía en Europa. No obstante, insistimos en advertir que Francisco y Lorenzo Durini se mantuvieron en tránsito entre América y Europa, lo cual se ejemplifica con el caso arriba analizado y fue una constante durante sus más de dos décadas de actividad comercial en Centroamérica.

Francisco Durini expandía entonces sus negocios hacia el sur de la región, mientras su hermano ofertaba sus servicios al mercado hondureño y partía a Europa para reincorporarse a sus labores habituales. En su aviso, Lorenzo Durini se promocionó en Honduras como comerciante de obras de mármol, licores y alimentos, pero enfatizó su oferta de piezas marmóreas. ${ }^{104}$ Es probable que los Durini hayan vendido mármol a particulares salvadoreños y hondureños durante el primer lustro de la década de 1880; sin embargo, tal asunto sobrepasa los objetivos de nuestra investigación.

\section{Conclusiones}

La reconstrucción de parte de las actividades comerciales de los hermanos Durini Vasalli entre 1880 y 1883 en El Salvador y Honduras, nos permite generar una serie de conclusiones. En primera instancia, pudimos determinar con claridad la nacionalidad de los hermanos Durini. Antes de este proyecto la historiografía costarricense ${ }^{105}$ solía identificar a los Durini como italianos o genoveses, una confusión causada por ellos mismos y su publicidad. Ahora podemos afirmar que tanto Lorenzo como Francisco Durini eran ciudadanos del país que actualmente se conoce como Suiza, y logramos elucidar cuáles fueron las relaciones de los Durini con el Reino de Italia y las condiciones que llevaron a una suerte de nacionalidad doble.

Por otro lado, a la hora de hablar de Francisco y Lorenzo Durini, debemos siempre tener claro que, más que sólo artistas, los hermanos Durini

102 No hemos identificado quién era Manuel Sequeiros. Quizás el tegucigalpense que hospedó a Lorenzo Durini fue un comerciante homónimo, quien vivió en Tegucigalpa en la década de 1880. Oyuela, Esplendor y miseria de la minería en Honduras, p. 216.

Sin embargo, ésta es tan sólo una hipótesis que sugiere una ruta para clarificar la identidad de Sequeiros y las relaciones sociales de los Durini en la Honduras de 1883.

103 “Aviso”, La Gaceta, Tegucigalpa, 9 de diciembre de 1883, p. 4.

104 Ibíd.

105 Bariatti, Italianos en Costa Rica 1502-1952: de Cristóbal Colón a San Vito de Java; Fischel, El Teatro Nacional de Costa Rica: su historia. 
fueron comerciantes. Con la iniciativa de sus padres de movilizarse a Lima, Perú, la llegada de los Durini a América se vio marcada desde el inicio por motivos socioeconómicos, los cuales tenían en su centro el oficio de escultor, iniciado por su padre Giovanni Durini. La combinación de sus conocimientos en las artes con las habilidades mercantiles dio comienzo a un negocio artístico sumamente exitoso, el cual movilizaba piezas entre Europa y América, estableciendo las relaciones mercantiles de forma directa con los gobiernos latinoamericanos.

Francisco Durini fue quien inició las relaciones comerciales en la región centroamericana y el primer sitio al que arribó, según hemos logrado corroborar, fue El Salvador, en contraste con otras propuestas que lo sitúan en Tegucigalpa. San Salvador fue el centro de operaciones de Francisco Durini en Centroamérica entre 1880 y 1883. Sus primeros contratos en el mercado artístico de la región fueron posibles gracias al interés de los gobernantes de El Salvador y Honduras por utilizar monumentos escultóricos para fomentar en la población determinadas identidades nacionales y promover la idea de unión centroamericana como algo necesario para el progreso del istmo.

En línea con los deseos de la república salvadoreña por crear una identidad unificada en la que el pueblo pudiera reflejarse, y a su vez vincularse con las otras naciones centroamericanas, el Estado mandó a construir el primer monumento que conocemos realizado por vía de Francisco Durini en Centroamérica: el monumento a Francisco Morazán (1880-1882). Participar en dicha obra provocó que la fama del suizo-italiano se expandiera internacionalmente y eso nos hace hipotetizar que tal vez eso llevó a Durini a trabajar en el monumento hondureño a Morazán (1882-1883). Morazán fue en esos años la figura por antonomasia de la construcción identitaria de sendas naciones y Francisco Durini fue el artífice de los dos monumentos del caudillo. De esta manera, un artista y comerciante europeo participó como proveedor artístico en dos proyectos políticos para la formación de identidades nacionales e identidades regionales centroamericanas.

En el proceso de erección del monumento a Morazán, hemos además propuesto una nueva hipótesis relativa a la participación de Lorenzo Durini en tal trabajo, lo que nos da los primeros indicios del arribo de Lorenzo a América Central. Movilizándose entre Tegucigalpa y El Salvador, llegamos a tener conocimiento de que Lorenzo Durini actuó como representante de su hermano mientras éste se encontraba en Génova gestionando, entre otras cosas, las piezas que conformarían el monumento.

Entonces, gracias a sus labores en El Salvador, Francisco Durini forjó los lazos necesarios para obtener con éxito varios contratos con el Estado hondureño, que lo llevó a producir una serie de monumentos. Esto posibilitó que el negocio artístico de Francisco Durini llegara a tener bases más sólidas para las futuras contrataciones, y que la participación directa de su hermano 
en los negocios centroamericanos fuese cada vez mayor. La fama es evidente aun en suelo europeo, con la mención de Francisco Durini en los periódicos italianos, los cuales demuestran a su vez la importancia para los países centroamericanos la visualización de un artista como Durini en cuanto a su naturaleza de heredero del arte italiano, el arte ideal y bello por excelencia dentro del imaginario de las esferas intelectuales del momento. Durini puede ser entendido entonces como un puente cultural entre los anhelos de Centroamérica por un pueblo unido en ideales de orden y progreso, representado por un ideal artístico que reflejase nociones de civilización y prosperidad, y el arte italiano, cuya notoriedad se debía a una concepción idealizada de las artes del pasado, el Renacimiento y el rescate de la Antigüedad grecorromana.

A su vez, el accionar comercial de los Durini en El Salvador y Honduras estableció un puente entre la industria artística italiana y el mercado centroamericano. De ese modo, los Durini fortalecieron los vínculos del mercado artístico europeo con Centroamérica, inicialmente con los gobernantes de El Salvador y Honduras, y con ello contribuyeron con el cambio cultural promovido por las élites de esos países. Gracias a ello, en los años siguientes los Durini consolidaron su presencia en sendos mercados centroamericanos y, poco a poco, expandieron sus redes comerciales a lo largo de América Central.

De hecho, el mes anterior a la despedida de Lorenzo Durini de la sociedad tegucigalpense, Francisco Durini se presentó ante el floreciente mercado artístico costarricense, y se quedó allí por aproximadamente dos meses. ${ }^{106}$ Así, con sus éxitos en El Salvador y Honduras llevándose a cabo, Durini decidió expandir más su negocio, presentándose en la escena artísticomercantil costarricense a finales de 1883. En Costa Rica los Durini no colocaron obras asociadas con los héroes del unionismo centroamericano, sino con el ideario de las élites costarricenses.

\section{BIBLIOGRAFÍA}

Bariatti, Rita, Italianos en Costa Rica 1502-1952: de Cristóbal Colón a San Vito de Java, San José, UACA, 2001.

Bochicchio, Luca, "La contribución italiana a la imagen monumental —escultórica y arquitectónica - de la independencia en Honduras”, Revista Kaypunku, vol. 2, núm. 1, 2015, pp. 13-29.

Cámara de Comercio Suiza en el Perú, Presencia Suiza en el Perú, Lima, Pacific Press S.A., 1991.

106 “Francisco A. Durini”, La Gaceta, San José, 16 de noviembre de 1883, p. 1103. 
Capello, Ernesto, City at the Center of the World: Space, History, and Modernity in Quito, Pittsburgh, University of Pittsburgh Press, 2011.

Chiaramonte, Gabriella, "La migración italiana en América Latina. El caso peruano”. Apuntes, núm. 13, 1983, pp. 15-36.

Cifuentes López, José Danilo. "Las esculturas de la Avenida Reforma como medio de identidad histórica guatemalteca”, tesis de licenciatura en Arte, Universidad de San Carlos de Guatemala, 2013.

Durini R., Pedro M., El Salvador Monumental y sus obras hermanas en América, Quito, Pedro M. Durini. R., 1996.

Fishel Volio, Astrid, El Teatro Nacional de Costa Rica: su historia, Costa Rica, Editorial Teatro Nacional, 1992.

González Galeotti, Juana Victoria, "La impronta italiana en las esculturas del Cementerio General de Guatemala (1881-1920)”, tesis de licenciatura en Arte, Universidad de San Carlos de Guatemala, 2006.

Gutiérrez, Ramón, Arquitectura y urbanismo en Iberoamérica, Madrid, Ediciones Cátedra, 1983.

Gutiérrez Viñuales, Rodrigo, “Carrara nell’America Latina e creazione scultorea”, en Carrara e il Mercato della Scultura 1870-1930, editado por Sandra Berresford, Milán, Federico Motta, 2007, pp. 254-259.

, "Presencia de Italia en la pintura y la escultura de los países sudamericanos durante el siglo XIX”, en Artisti italiani in America latina. Presence, contatti, commerci, Roma, La Nuova Italia Scientifica, 1997, pp. 35-46.

Hobsbawm, Eric, La era del capital: 1848-1875, Buenos Aires, Paidós/Crítica, 2010.

Hughes, Steven C., “Ticino. A History of the Cantons. Unfinished and Unpublished”, University of Kent, 2006, https://www.kent.ac.uk/politics/cfs/csp/pdf/ 09LTICINO.pdf, consultado el 4 de mayo de 2015.

León Sáenz, Jorge, Evolución del comercio exterior y del transporte marítimo de Costa Rica: 1821-1900, San José, EUCR, 2002.

Leonardini, Nanda, "Presencia e imagen femenina en la escultura italiana en el Perú del siglo XIX”, Escritura y Pensamiento, vol. 4, no. 7, 2001, pp. 109-123.

Lindo Fuentes, Héctor, “Economía y sociedad (1810-1870)", en Historia general de Centroamérica, tomo III, editado por Héctor Pérez Brignoli. Madrid, Sociedad Estatal Quinto Centenario-Facultad Latinoamericana de Ciencias Sociales, 1993, pp. 141-201.

López Bernal, Carlos Gregorio, "Poder central y poder local en la construcción del Estado en El Salvador, 1840-1890”, tesis de doctorado en Historia de América Central, Universidad de Costa Rica, 2007.

, "Inventando tradiciones y héroes nacionales: El Salvador (1858-1930), Revista Historia de América, núm. 127, 2000. Disponible en https://www.academia.edu/529224/Inventando tradiciones y h\%C3\%

A9roes_nacionales_El_Salvador_1858-1930_ consultado el 29 de abril de 2019. 
_ , "El proyecto liberal de nación en El Salvador (1876-1932)”, tesis de maestría en Historia, Universidad de Costa Rica, 1998.

Oviedo Salazar, Mauricio y Santamaría Montero, Leonardo, “Mercato culturale: El nacimiento de la ornamentación de un Coliseo”, Diálogos: Revista Electrónica de Historia, vol. 16, núm. 2, 2015, pp. 27-57.

Oyuela, Leticia de, Esplendor y miseria de la minería en Honduras, Tegucigalpa, Editorial Guaymuras, 2003.

Pavoni, Rosanna (ed.), Reviving the Renaissance: the use and abuse of the past in nineteenth-century Italian art and decoration, Cambridge, Cambridge University Press, 1997.

Pevsner, Nikolaus, Historia de las tipologías arquitectónicas, Barcelona, Editorial Gustavo Gili, S. A., 1979.

Pino Martínez, Inés del, “Gestión y arte en el espacio público: la contribución de los 'Durini' en América (1880-1930)”, Índex, revista de arte contemporáneo, núm. 4, 2017, pp. 13-29.

— Los Durini: Artífices del rostro moderno de Quito. Análisis de la arquitectura en un marco socio-histórico, Quito, inédito, 2012.

Quesada Avendaño, Florencia, “La modernización entre cafetales. San José, Costa Rica, 1880-1930”, tesis doctoral en Estudios Latinoamericanos, Universidad de Helsinki, 2007.

Rosa, Ramón, “Decreto”. Revista del Archivo y Biblioteca Nacional de Honduras, vol. 1, núm. 15, 1901, p. 438.

Rosa, Ramón y Durini, Francisco, “Contrata”, Revista del Archivo y Biblioteca Nacional de Honduras, vol. 1, núm. 15, 1901, pp. 438-439.

Santamaría Montero, Leonardo, “Análisis de la conformación del diseño arquitectónico y ornamental del Teatro Nacional de Costa Rica”, tesis de licenciatura en Historia del Arte, Universidad de Costa Rica, 2017.

Santamaría Montero, Leonardo y Oviedo Salazar, Mauricio, "Los hermanos Durini y las Casas de Corrección en Costa Rica”, Cuadernos Inter.c.a.mbio sobre Centroamérica y el Caribe, vol. 12, núm. 2, 2015, pp. 17-42.

Taracena Arriola, Arturo, "Liberalismo y poder político en Centroamérica (18701929)”, en Historia general de Centroamérica, tomo IV, editado por Víctor Hugo Acuña Ortega. Madrid, Sociedad Estatal Quinto Centenario-Facultad Latinoamericana de Ciencias Sociales, 1993, pp. 167-253.

Tavernor, Robert, Palladio and Palladianism, London, Thames \& Hudson.

Toman, Rolf (ed.), Neoclasicismo y romanticismo, Alemania, Könemann Verlagsgesellschaft mbH.

Torrejón Mora, José Vicente, "Escultura monumental pública de Tegucigalpa”, NORBA-ARTE, vol. 17, 1997, pp. 149-163.

Valdés Valle, Roberto Armando, "Masones, liberales y ultramontanos salvadoreños: debate político y constitucional en algunas publicaciones impresas, durante la 
etapa final del proceso de secularización del Estado salvadoreño (18851886)”, tesis doctoral en Filosofía Iberoamericana, Universidad Centroamericana José Simeón Cañas, 2010.

Zanutelli Rosas, Manuel, La huella de Italia en el Perú. Lima, Fondo Editorial del Congreso del Perú, 2001.

\section{Fuentes inéditas}

Archivo Nacional de Costa Rica, serie Fomento.

Archivo Nacional de Honduras, serie Fomento.

\section{Publicaciones periódicas}

Diario Oficial, San Salvador, El Salvador.

La Gaceta, San José, Costa Rica.

La Gaceta, Tegucigalpa, Honduras.

La Paz, Tegucigalpa, Honduras.

La República, San Salvador, El Salvador. 